Research Article

\title{
Hot Water Preparation along with Combined Solar Thermochemical Energy Storage System: Experimental Validation and Performance Simulation
}

Oleksandr Skrylnyk ${ }^{\dagger,}{ }^{*}$, Emilie Courbon $^{\dagger}$, Nicolas Heymans $^{\dagger}$, Marc Frère $^{\dagger}$

Department of Thermodynamics and Mathematical Physics, University of Mons, Boulevard Dolez 31, Mons, Belgium; E-Mails: oleksandr.skrylnyk@umons.ac.be; emilie.courbon@umons.ac.be; nicolas.heymans@umons.ac.be; marc.frere@umons.ac.be

+ These authors contributed equally to this work.

* Correspondence: Oleksandr Skrylnyk; E-Mail: oleksandr.skrylnyk@umons.ac.be

Academic Editor: Joaquin Alonso-Montesinos

Special Issue: Photovoltaic Solar Systems and Solar Thermal Plants

Journal of Energy and Power Technology

2021, volume 3, issue 2

doi:10.21926/jept.2102017
Received: December 18, 2020

Accepted: March 22, 2021

Published: April 14, 2021

\begin{abstract}
Hybrid solar thermal systems are considered to be a promising solution for delivering clean thermal energy for the building sector, especially while combining them with other renewable energy sources. Usually, solar energy production does not match the thermal energy demand, and hence the energy storage must be integrated. Thermochemical energy storage is adapted particularly to be used along with solar thermal applications. In this article, the design of the combined solar thermochemical energy storage system is presented. The experimental prototype was built and tested within atmospheric conditions. The model of the thermochemical reactor was developed using Matlab $^{\circledR}$ and it was validated by the experimental data. The dynamic simulations of the combined solar thermal system for the preparation of domestic hot water were carried out in the TRNSYS environment. The experimental energy storage density of the fully dehydrated material under non-equilibrium conditions was measured between 102 and $158 \mathrm{kWh} / \mathrm{m}^{3}$. Dynamic simulations performed in
\end{abstract}

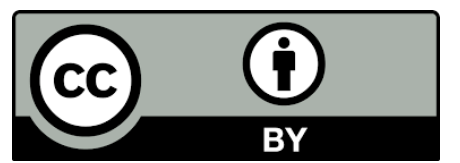

(C) 2021 by the author. This is an open access article distributed under the conditions of the Creative Commons by Attribution License, which permits unrestricted use, distribution, and reproduction in any medium or format, provided the original work is correctly cited. 
a broader scope of climate conditions showed that the energy storage density in the material under non-equilibrium conditions could vary between 71 and $247 \mathrm{kWh} / \mathrm{m}^{3}$.

\section{Keywords}

Thermochemical energy storage; solar system; domestic hot water; composite material

\section{Introduction}

The idea of using thermochemical energy storage based on solid/gas adsorption process in heating and cooling applications gained special attention since the early 90s [1]. The depletion of the ozone layer and global warming were the major driving factors to the onset of the development of solid/gas adsorption technology in heat transforming devices [2]. Initially, the research efforts on the refrigeration cycles having solid/gas adsorption processes dominated over the applications of heat storage and heat generation due to the pre-disposed international legislation brought over on account of the production and consumption of ozone-depleting substances. The adaptation of the world-wide legislation for the promotion of renewable energy production and energy efficiency, along with the decarbonization of the energy sector, resulted in the massive development of various concepts of heat storage systems integrated with the thermochemical process [3].

The solid/gas adsorption principle is based upon the reversible reaction of the gas on the porous solid between the inlet and outlet boundary conditions that are set by temperature and partial pressure. The capturing of gas molecules by a porous solid is an exothermic reaction that is responsible for the heat release, which could be used for immediate heat production. Once the solid/gas equilibrium is attained, the solid must be regenerated to the initial state. Solid regeneration is an endothermic reaction, and it is typically performed by supplying external heat to the solid material. The thermal energy is thus stored in the form of chemical potential.

The integration of thermochemical energy storage in thermal solar systems is one of the effective technological opportunities that deliver clean energy to consumers. Merging the thermochemical process with thermal solar technology is a relatively familiar concept.

However, the commercialization of combined solar thermochemical plants at various scales has not yet reached steady progress. The global technology readiness level oscillates between 5 and 7 , while the energy storage costs remain quite high [4]. The ecological aspects, high energy storage density, and the absence of energy loss during the storage period are the biggest advantages of the thermochemical process. Combined small-scale heat storage systems are more suitable for utilization in the residential building sector for space heating and domestic hot water production. These systems are typically operated between $30^{\circ} \mathrm{C}$ and $100{ }^{\circ} \mathrm{C}$ as boundary conditions.

Fundamentally, thermochemical energy storage concepts for the residential sector are divided into closed systems and open sorption systems. It must be noted that this study considers only concepts concerning the production of domestic hot water or concepts being potentially easily reconfigurable for this purpose.

Closed sorption systems usually work under conditions below atmospheric pressure, and the solid material is deposited on the specially designed adsorbent heat exchanger [5]. Roumpedakis et al. studied a solar-driven hybrid adsorption system made for heating and cooling in buildings [6]. 
The system consisted of $40 \mathrm{~m}^{2}$ of evacuated tubes solar collectors that were connected to a 12.5 kW zeolite-water adsorption chiller. Researchers reported the great potential that this configuration possessed for the decarbonization of residential energy systems. Wang et al. proposed a hybrid solar adsorption apparatus for water heating and ice-making by using an activated carbon-methanol chemical couple [7]. The experimental apparatus was adjusted to prepare 112-150 kg of hot water at $91.3-98{ }^{\circ} \mathrm{C}$ and nearly $10 \mathrm{~kg}$ of ice with the help of solar collectors and $22 \mathrm{~kg}$ of activated carbon. The coefficient of performance obtained by the prototype was close to 0.4 , and the system efficiency varied between $76 \%$ and $90 \%$. Ji et al. developed a solar, hot water-driven, vacuum adsorption system for making ice using activated carbon-methanol as a working pair [8]. The icemaking capacity of the prototype was $8.4 \mathrm{~kg}$ per day, with the lowest temperature reaching $-8.4{ }^{\circ} \mathrm{C}$ and hot water temperature maintained at $94{ }^{\circ} \mathrm{C}$. The best coefficient of performance was recorded as high as $\sim 0.14$, and the system heat utilization efficiency was close to $54 \%$. Zhao et al. designed a closed sorption heat storage apparatus for the preparation of domestic hot water using lithium chloride-water chemical couple [9]. The energy storage density of the sorption device was nearly 65 $\mathrm{kWh} / \mathrm{m}^{3}$ at charging and discharging temperatures of $85^{\circ} \mathrm{C}$ and $40{ }^{\circ} \mathrm{C}$, respectively. The total heat storage efficiency was as high as $94 \%$.

Concerning open sorption systems, the design is generally limited to the use of humid air. This type of system consists of open inlet and outlet boundaries, with the flowing humid air being in direct contact with the solid [10]. For such systems, the exothermic reaction leads to material hydration, while the dehydration of the material is achieved by an endothermic reaction. Gaeini et al. constructed open sorption, multi-modular, thermochemical energy storage for domestic hot water production using a zeolite-water working pair [11]. The average experimental energy storage density was $108 \mathrm{kWh} / \mathrm{m}^{3}$ at the reactor scale with charging and discharging temperatures of $190{ }^{\circ} \mathrm{C}$ (hot air) and $10{ }^{\circ} \mathrm{C}$ (outdoor humid air). The average combined thermal power output was nearly $3.6 \mathrm{~kW}$ at a period of $10 \mathrm{~h}$. The following examples describe space heating systems that could be potentially converted to produce domestic hot water. Michel et al. developed large-scale, open sorption, thermochemical energy storage for building heating that consisted of a stack of packed beds filled with $400 \mathrm{~kg}$ of hydrated strontium bromide [12]. The prototype was able to store up to $105 \mathrm{kWh}$, and its energy storage density was $203 \mathrm{kWh} / \mathrm{m}^{3}$. Aydin et al. tested a prototype of an open sorption modular reactor for solar thermal energy storage [13]. The authors focused on the evaluation of the vermiculite-calcium chloride composite material reacting with humid air. The energy storage density on the material scale varied from 33 to $100 \mathrm{kWh} / \mathrm{m}^{3}$ depending on the air humidity and the inlet air temperature, which was set between $14{ }^{\circ} \mathrm{C}$ and $21^{\circ} \mathrm{C}$. The average thermal power output of the reactor varied between $313 \mathrm{~W}$ and $730 \mathrm{~W}$.

These examples give a general idea about the performance characteristics of various thermochemical energy storage devices used with solar thermal systems. The choice of the technology used (closed or open sorption reactor) is mostly determined by the working pair, targeted application (heat storage or heat transformation), and the time scale between energy charging and discharging. However, the differences in the techno-economic performances between the closed and open sorption systems are not as significant as shown in studies by Scapino et al. [4], and Bertsch et al. [14]. Moreover, the comparison of performance characteristics for various systems presented in the literature is difficult to be carried out due to the lack of a common calculation methodology for the key performance indicators, as discussed by Palomba et al. [15]. 
In this article, a combined solar thermal system with open sorption, thermochemical energy storage is designed and validated. The combined system is dedicated to the preparation of domestic hot water in residential buildings. The novelty of the work consists of the following. First, the intermediate scale prototype of the thermochemical energy storage system was built and experimentally tested by using the recently developed composite solid adsorbent. Second, the experimental data were used to validate the mathematical model of the thermochemical reactor. The apparent kinetic coefficient was represented by the grey-box model along with a sigmoidshaped function. Finally, the in-depth study of the dynamic behavior of the combined solar energy system with an account of the consumption profile of domestic hot water was conducted by using the numerical simulation approach in the TRNSYS environment for the daily and typical climatic conditions in Brussels (Belgium). The lead-off automation algorithm was proposed to study the dynamic behavior of the combined solar system. This article contributes to the design of the thermochemical energy storage devices coupled to the solar thermal systems present in residential buildings. The results of the work are helpful to bridge the gap in the academic knowledge concerning the integration of thermochemical energy storage to hybrid heating systems.

\section{Materials and Methods}

\subsection{Thermochemical Energy Storage}

The combined solar energy system integrates thermochemical energy storage, and it is primary designed for the preparation of domestic hot water in a residential building. As the production of hot water is mainly due to the adsorption process, the study of the system configuration was adjusted in this mode. The desorption mode was not included in the present study. The system's design in the adsorption mode is shown in Figure 1. Conceptually, the system consists of an array of solar thermal collectors (1), a hot water storage tank (2), a modular open sorption thermochemical reactor (3), and a back-up thermal device (4). Under ideal conditions, the working principle of the combined system is as follows. During a period of low solar irradiance, the water storage tank (2) is heated up by the adsorption process (3) until all the adsorbent beds (modules) reach a hydrated state and no further significant heat generation by the exothermic reaction is possible. To do this, first, the outside cold and humid air at a temperature $T_{a}$ is pre-heated through the heat exchanger $H X_{2}$. Afterward, the warm and humid air is blown constantly from the heat exchanger $H X_{2}$ to the reactor (3) through the fan $F_{1}$. The reaction heat is used to charge the water tank (2) through the air-to-water heat exchanger $H X_{1}$. The expected charging temperature of the water tank ranges from $40{ }^{\circ} \mathrm{C}$ to $50^{\circ} \mathrm{C}$, which roughly allows the energy storage density in the material to be between $120 \mathrm{kWh} / \mathrm{m}^{3}$ and $150 \mathrm{kWh} / \mathrm{m}^{3}$. The air-to-air heat exchanger $H X_{2}$ is also used for heat recovery; thus, it allows the rejected reaction heat to be re-injected to the heating process. During the period of high solar irradiance, the charge of the water storage tank (2) is continued by the array of solar thermal collectors (1) until the water temperature reaches a usable level between $60^{\circ} \mathrm{C}$ and $90{ }^{\circ} \mathrm{C}$. By default, the solar thermal collectors are glazed flat plate collectors. However, evacuated tubes or concentrated solar thermal collectors can be plugged too. The back-up thermal device (4) is only used in case of a mismatch $\left(T_{D H W \text {,out }}<T_{D H W}^{0}\right)$ of the tank outlet temperature $T_{D H W \text {,out }}$ with the reference temperature profile of the user $T_{D H W}^{0}$. The working cycle of the hydraulic pump $P_{1}$ is controlled by the solar thermal collectors, while the hydraulic pump $P_{2}$ is simultaneously activated or disabled with the fan $F_{1}$. 


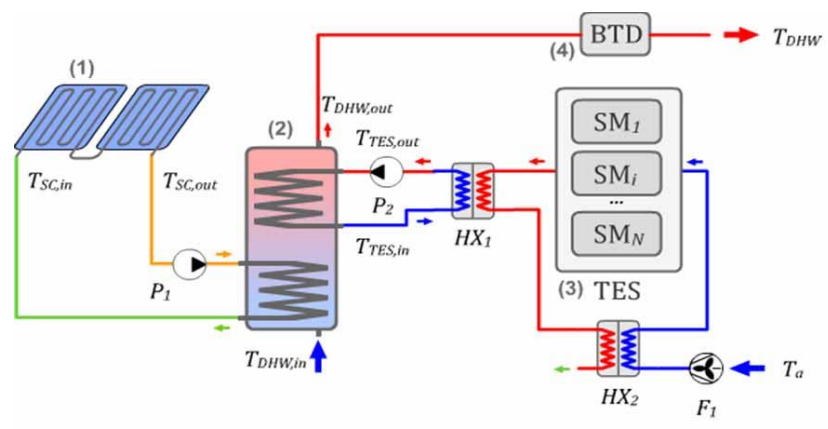

Figure 1 Combined solar thermal system with thermochemical energy storage.

The thermochemical reactor (3) is assembled from removable storage modules $S M_{i}, i=\overline{1 \ldots N}$ each filled with solid adsorbent. The modules are stacked horizontally, and they are assembled in such a way that the inlet air flows in a cross-sectional direction through the surface area of each of the modules. Modules with hydrated solid are replaced by the modules with dehydrated material that is available in the stock. Conceptually, each storage module is designed as a rectangular tray with dimensions $L \times W \times H$, respectively representing the module's length, width, and depth. The solid adsorbent is confined between the tightly stretched upper and lower metallic sieves. The schematic presentation of a storage module is shown in Figure 2.

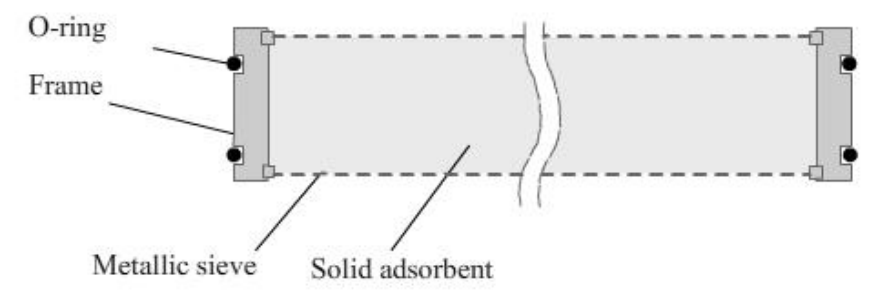

Figure $\mathbf{2}$ Schematic representation of the storage module.

\subsection{Solid Adsorbent}

The solid adsorbent used in this procedure is a composite material that reacts with water vapor. The composite material consists of a mesoporous matrix having trapped salt of calcium chloride $\left(\mathrm{CaCl}_{2}\right)$. The mesoporous matrix is the Davisil ${ }^{\circledR}$ silica gel (grade 62) from $\mathrm{Grace}$. The $\mathrm{CaCl}_{2}$ was supplied by Solvay in the form of anhydrous Caso ${ }^{\circledR}$ granulate. This composite was developed at the Research Institute for Energy at the University of Mons (Belgium), and it was tested with various sample scales in prototype installations as reported by Skrylnyk et al. [16] and Wyttenbach et al. [17]. This composite adsorbent was synthesized using a patented multi-step wetness incipient impregnation method. This method allowed a high salt content to be reached ( $43 \mathrm{wt.} \%$ ) inside silica gel. A detailed description of the synthesis procedure has been given by Courbon et al. [18]. Afterward, the synthesized sample was characterized by commonly used methods. The reaction heat was determined from the thermal gravimetric and differential scanning calorimetric analysis using TGA/DSC 111, which was connected to the Wetsys humidifier from Setaram. The water adsorption isotherms were obtained from dynamic vapor sorption tests using IGASorp from Hiden Isochema. The porous characteristics were measured using nitrogen sorption measurements at 77 $\mathrm{K}$ by using Belsorp-max from BEL-Japan. The total volume of the pores was determined at $p_{v} / p_{v}^{0}=$ 
0.99, while the specific surface area was obtained by the Brunauer-Emmett-Teller method. The properties and characteristics of this composite adsorbent are presented in Table 1 . The water adsorption isotherms are shown in Figure 3.

Table 1 Characteristics of the silica- $\mathrm{CaCl}_{2}$ composite adsorbent [18].

\begin{tabular}{ll}
\hline Characteristic & Value \\
\hline Reaction heat $\left(\mathrm{kJ} / \mathrm{kg}_{\mathrm{H} 2 \mathrm{O}}\right)$ & 2757 \\
Total volume of the pores $\left(\mathrm{cm}^{3} / \mathrm{g}\right)$ & 0.38 \\
Specific surface area $\left(\mathrm{m}^{2} / \mathrm{g}\right)$ & 75 \\
Packing density of anhydrous material $\left(\mathrm{kg} / \mathrm{m}^{3}\right)$ & 703 \\
Average particle size $(\mu \mathrm{m})$ & 390 \\
\hline
\end{tabular}

Figure 3 Water adsorption isotherms of water sorption on the silica- $\mathrm{CaCl}_{2}$ composite material [18].

\subsection{Experimental Procedure}

The collection of experimental data for the adsorption mode was performed in a prototype installation, whose design slightly differed from the original concept, which was presented in Figure 1. The scale of the experimental prototype was also adjusted to study the adsorption mode. The reactor (3) consisted of a single storage module with a capacity to hold $2.5 \mathrm{~kg}$ of solid. The volume of the water storage tank was $50 \mathrm{~L}$. The airflow rate of the fan was set to $100 \mathrm{~m}^{3} / \mathrm{h}$. No solar collectors or back-up thermal devices were used. The water was not consumed from the tank during thermal charge. The storage module was fully instrumented, and it was mounted inside a metallic housing. The instrumentation scheme of a single storage module is shown in Figure 4 . The geometric data of the storage module are presented in Table 2, and the technical characteristics of measuring instruments are presented in Table 3. 


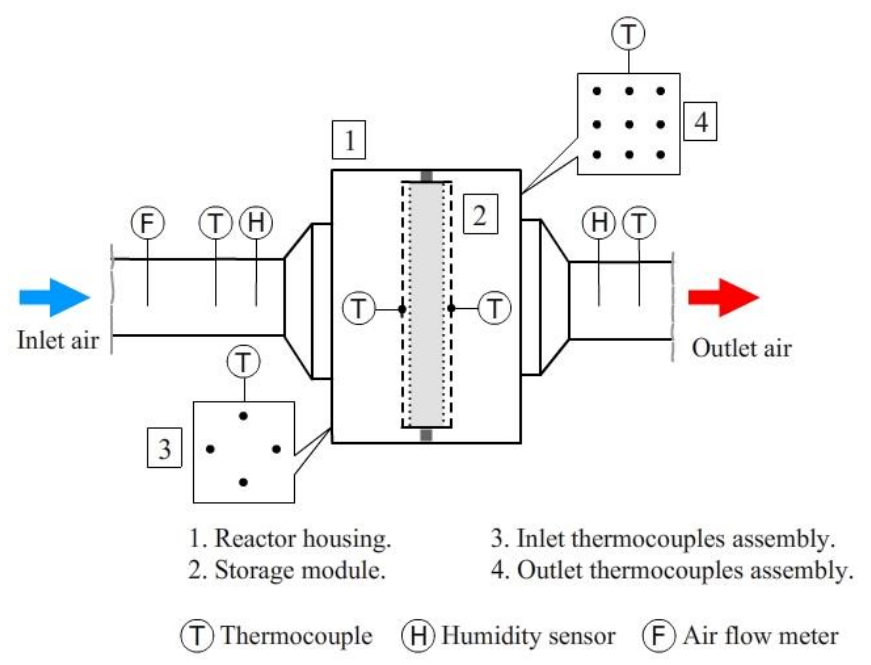

Figure 4 Instrumentation of a single storage module.

Table 2 Size characteristics of the experimental storage module.

\begin{tabular}{ll}
\hline Characteristic & Value \\
\hline Width $(\mathrm{m})$ & 0.60 \\
Length $(\mathrm{m})$ & 0.52 \\
Depth $(\mathrm{m})$ & 0.01 \\
Capacity $(\mathrm{kg})$ & 2.5 \\
Volume $\left(\mathrm{m}^{3}\right)$ & $3.12 \times 10^{-3}$ \\
\hline
\end{tabular}

Table 3 Technical characteristics of the measuring equipment.

\begin{tabular}{lll}
\hline Instrument & Precision & Range \\
\hline Thermocouple standard, type $\mathrm{K}$ & $0.75 \%$ & $-270-1370{ }^{\circ} \mathrm{C}$ \\
Humidity sensor, VAISALA HMP5 & $\pm 0.8 \%$ RH. at $40-0-100 \%$ R.H., $-70-$ \\
& $95 \%$ R.H. & $80{ }^{\circ} \mathrm{C}$ \\
Air flow meter, HÖNTZCH FA ZS30 & $\pm 0.01 \mathrm{~m} / \mathrm{s}$ & $0.3-2 \mathrm{~m} / \mathrm{s}$ \\
Water flow meter, NATEC FT2 & $< \pm 0.07 \mathrm{l} / \mathrm{min}$ & $0.15-4.5 \mathrm{l} / \mathrm{min}$ \\
\hline
\end{tabular}

The experimental procedure was as follows: first, the composite was dehydrated in an oven at $150^{\circ} \mathrm{C}$ for $24 \mathrm{~h}$. Then the composite was loaded in the storage module inside the reactor. Afterward, the composite was hydrated for approximately $1 \mathrm{~h}\left(t_{\max }\right)$ by blowing ambient humid air through the reactor. The experimental data of the temperature and humidity at the inlet and outlet of the reactor, as well as the temperature on both sides of the storage module (see Figure 4), were recorded in the computer using the data acquisition system CompactDAQ from National 
Instruments. Finally, the following treatment procedure was applied to the measured data. The calculation of the water uptake was done with the following formula:

$$
x_{s}(t)=\frac{1}{m_{s}} \int_{t_{0}}^{t_{\max }} \dot{m}_{a} \cdot \Delta w_{v}(t) \mathrm{d} t
$$

Here, $m_{s}$ is the mass of the solid in the storage module, $\dot{m}_{a}$ is the dry air mass flow rate, and $\Delta w_{v}=w_{v, \text { out }}-w_{v, \text { in }}$ is the difference between air humidity measured at the inlet $w_{v, \text { in }}$ and outlet $w_{v, \text { out }}$ of the reactor. The thermal power produced at the reactor's boundaries was determined as follows:

$$
\dot{Q}_{\mathrm{a}}(t)=\dot{m}_{\mathrm{a}} C_{\mathrm{P}, \mathrm{a}} \cdot \Delta T_{a}(t)
$$

$C_{\mathrm{P}, \mathrm{a}}$ is the thermal capacity of the dry air, $\Delta T_{a}$ is the variation in air temperature measured between the inlet and outlet of the reactor. Note that equation (2) refers to the sensible heat flow added in the air by the adsorption reaction. It was also considered that the water present in the water storage tank was heated via the heat exchanger $H X_{1}$ thanks to the sensible heat. No condensation occurred in the heat exchanger $H X_{1}$ during thermal charge.

Thermal energy produced by the reactor was calculated by the following formula:

$$
E_{r}=\int_{t_{0}}^{t_{\max }} \dot{Q}_{a}(t) \mathrm{d} t
$$

Energy storage density at the material scale was determined from the following relation:

$$
\Delta E_{r}=\rho_{s} \frac{E_{r}}{m_{s}}
$$

Here $\rho_{s}$ is the volumetric mass of the anhydrous composite.

\subsection{Modeling and Simulation Methods}

\subsubsection{Reactor Modeling}

The modeling of the reactor is based on the following considerations. Given, a micro-granular porous solid consisting of spherical particles of the same diameter $d_{p}$ is packed in a one-dimensional bed having a height $L_{b e d}$ and width $d_{b e d}$. The humid air flows with a constant linear velocity $u_{g}$ through the porous solid in the direction perpendicular to the surface area of the bed. The onedimensional packed bed is presented in Figure 5. The effects of the radial dispersion of the carrier gas (dry air) in a porous medium are neglected in the model. 


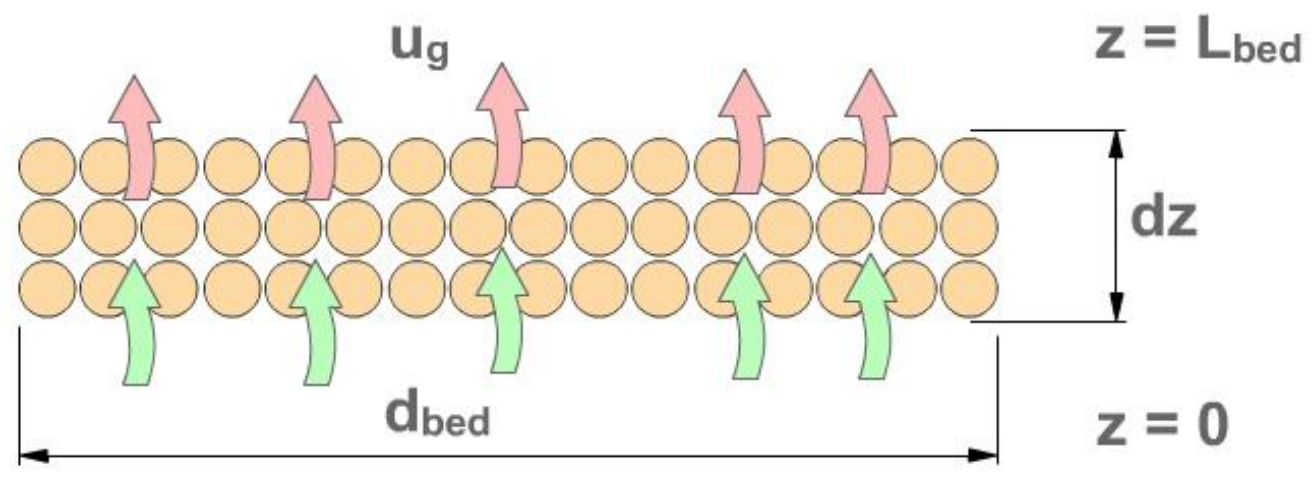

Figure 5 Presentation of a packed adsorption plate for reactor modeling.

The adsorption of water vapor on the composite is modeled by a set of the following mathematical equations. The mass balance of the humidity content $w_{v}$ in the flowing air is written as follows:

$$
\rho_{a} \frac{\partial w_{v}}{\partial t}+\frac{\partial}{\partial z}\left(u_{g} \rho_{a} w_{v}\right)=D_{L} \rho_{a} \frac{\partial^{2} w_{v}}{\partial z^{2}}+(-1) \cdot \rho_{s} \cdot\left(\frac{1-\varepsilon}{\varepsilon}\right) \cdot \frac{\partial x_{s}}{\partial t}
$$

Here, $D_{L}$ is the diffusivity of the water vapor along the $z$ axis.

The variation of the temperature of humid air $T_{g}$ flowing through the porous medium along the $z$ axis is written as follows:

$$
\rho_{g} C_{p, g} \frac{\partial T_{g}}{\partial t}+\frac{\partial}{\partial z}\left(u_{g} \rho_{g} C_{p, g} T_{g}\right)=\lambda_{L} \frac{\partial^{2} T_{g}}{\partial z^{2}}+h_{0} \frac{6}{d_{p}} \cdot\left(\frac{1-\varepsilon}{\varepsilon}\right) \cdot\left(T_{s}-T_{g}\right)
$$

With $\lambda_{L}=D_{L} C_{p, g} \rho_{g}$ being the thermal diffusivity and $h_{0}$ being the heat transfer coefficient. Equations (5) and (6) are coupled to the following mass and heat balance equations (7) and (8) in the solid medium. The variation of the water uptake $x_{s}$ in solid is modeled by the following equation:

$$
\frac{\partial x_{s}}{\partial t}=k_{o}\left(x_{s}^{0}-x_{s}\right)
$$

Here, $k_{0}$ is the kinetic coefficient and $x_{s}^{0}=x_{s}^{0}\left(T_{s}, p_{v}\right)$ is the water uptake under equilibrium conditions, which is determined from the isotherm characteristics, and which depends on the adsorption temperature $T_{s}$ and water vapor pressure $p_{v}$. The variation in temperature $T_{s}$ in a solid material is determined by the following energy balance equation:

$$
\rho_{s}\left(C_{p, s}+C_{p, w} x_{s}\right) \frac{\partial T_{s}}{\partial t}=h_{0} \frac{6}{d_{p}} \cdot\left(T_{g}-T_{s}\right)+\rho_{s} \frac{\partial x_{s}}{\partial t} \cdot \Delta H_{s}
$$

Here $\Delta H_{S}$ is the reaction heat, which is equal to $2757 \mathrm{~kJ} / \mathrm{kg}$ (see Table 1). The boundary conditions complete the adsorption model expressed by equations (5-8). In the present model, the Danckwerts boundary conditions are considered as discussed by Pearson's [19]. The conditions for mass transfer of humid air at the geometric boundaries are written as follows: 


$$
\begin{gathered}
-D_{L} \frac{\partial\left(\rho_{a} w_{v}\right)}{\partial z}=u_{g} \rho_{a} w_{v, i n}-u_{g} \rho_{a} w_{v}, \quad z=0^{+} \\
-D_{L} \frac{\partial\left(\rho_{a} w_{v}\right)}{\partial z}=0, \quad z=L_{b e d}
\end{gathered}
$$

The conditions for energy flow through the bed boundaries are set by the following equations:

$$
\begin{gathered}
-\lambda_{L} \frac{\partial T_{g}}{\partial z}=u_{g} C_{p, g, i n} \rho_{g, i n} T_{g, \text { in }}-u_{g} C_{p, g} \rho_{g} T_{g}, \quad z=0^{+} \\
-\lambda_{L} \frac{\partial T_{g}}{\partial z}=0, \quad z=L_{b e d}
\end{gathered}
$$

The heat transfer coefficient $h_{0}$ can be determined from the Nusselt number $N u=h_{0} d_{p}\left(\lambda_{g}\right)^{-1}$, where the Nusselt number is calculated using the following correlation given by Wakao et al. [20]:

$$
N u=2+1.1 \operatorname{Re}^{\frac{2}{3}} \operatorname{Pr}^{\frac{1}{3}}
$$

The thermal conductivity of the humid air is modeled using the Sutherland-Thiesen equation for binary mixtures as discussed by Buddenberg et al. [21]:

$$
\lambda_{g}=\sum_{i=\{a, v\}} \frac{\lambda_{i}}{1+a_{i} X_{m}}
$$

Here, $X_{m}$ is the molar fraction of the moisture present in the air, which is given as $X_{m}=$ $x_{v} M_{a}\left(M_{v}\right)^{-1}$, and $\mathrm{a}_{i}, i=\{a, v\}$ is the coefficient in the Sutherland-Thiesen equation being determined, respectively for $\operatorname{dry}$ air $(a)$ and water vapor $(v)$ as follows:

$$
a_{i}=\frac{1}{4}\left(1+\left(\frac{\mu_{i}}{\mu_{j}} \cdot\left(\frac{M_{i}}{M_{j}}\right)^{\frac{3}{4}} \cdot \frac{1+\frac{S_{i}}{T_{g}}}{1+\frac{S_{j}}{T_{g}}}\right)^{\frac{1}{2}}\right)^{2} \cdot\left(\frac{1+\frac{S_{a v}}{T_{g}}}{1+\frac{S_{i}}{T_{g}}}\right)
$$

With $\mu_{\{i, j\}}$ is the dynamic viscosity of each component in the binary mixture, $M_{\{i, j\}}$ is the molar mass of each component, and $S_{\{i, j\}}$ is the Sutherland constant. It must be noted that index $j=$ $\{v, a\}$ represents the permutation of the set $i$. The Sutherland constants for dry air and water vapor $S_{a}=111 \mathrm{~K}, S_{v}=961 \mathrm{~K}$ and $S_{a v}=0.733 \sqrt{S_{a} S_{v}}$.

The kinetic coefficient was identified from the experimental data using the following empirical relation (sigmoid-shaped function):

$$
\hat{k}_{o}=b_{0} \cdot\left[1-\operatorname{atan}\left(\left(x_{s}-b_{1}\right) \cdot b_{2}\right) b_{3}\right]
$$

The relation (14) can be written in general form as follows:

$$
\hat{k}_{o}=\widehat{K} \cdot F\left(x_{s}\right)
$$


where $\widehat{K}$ is the characteristic kinetic coefficient at the characteristic water uptake $x_{s}=b_{1}$. The characteristic kinetic coefficient is defined by the parameter $b_{0} . F\left(x_{s}\right)$ is the saturation-like correction term, $F\left(x_{s}\right) \in \mathbb{R}^{+}$, whose value is equal to $F\left(x_{s}\right)=1$ as the characteristic water uptake $x_{s}=b_{1}$. The characteristic water adsorption uptake is defined at a hydration level, in which significant changes in the water sorption mechanism occur.

The model parameters $b_{k}, k=0 \ldots 3$ in equation (14) were found by solving the following parametric identification problem:

$$
\min \left(\sum_{l=1}^{N}\left(\hat{k}_{o, l}\left(b_{k}\right)-\bar{k}_{o, l}\right)^{2}\right), \quad\left(\forall \hat{k}_{o, l}, \forall \bar{k}_{o, l}\right) \in \mathbb{R}^{+}
$$

where $\bar{k}_{o, l}$ is the experimental kinetic coefficient that was estimated for each $1 \leq l \leq N$ point in the measured datasets:

$$
\bar{k}_{o, l}=\frac{\dot{m}_{a} \cdot \Delta w_{v}}{m_{s} \cdot\left(x_{s}^{0}\left(T_{g, o u t}, \bar{p}_{v}\right)-x_{s}\right)}
$$

where $m_{s}$ is the mass of anhydrous solid, $x_{s}$ is estimated from the experimental data and with air humidity difference $\Delta w_{v}$ between the inlet and outlet of the reactor. It was hypothesized that the thermodynamic equilibrium $x_{s}^{0}$ depends on the average water vapor pressure between the inlet and outlet conditions of the reactor $\bar{p}_{v}=\frac{1}{2} \cdot\left(p_{v, \text { in }}+p_{v, \text { out }}\right)$ and that there is a thermal equilibrium between solid and gas in the outlet conditions $T_{g, o u t} \equiv T_{s}$.

\subsubsection{Combined Solar System Simulation}

In this study, the dynamic behavior of the combined solar system shown in Figure 1 was simulated in the TRNSYS environment. Firstly, the numerical model of the adsorption process described by the equations (6-10) was created using Matlab ${ }^{\circledR}$ software. Secondly, this model was integrated as a separate component in the simulation environment of the TRNSYS software. Finally, the technical components (e.g., reactor, heat exchangers, solar thermal collectors, water storage tank) were linked to recreate the combined solar energy system shown in Figure 1 . The climate data were linked to the boundary conditions of the reactor and other technical components. The principal scheme for the simulation of the system is provided in Figure 6. 


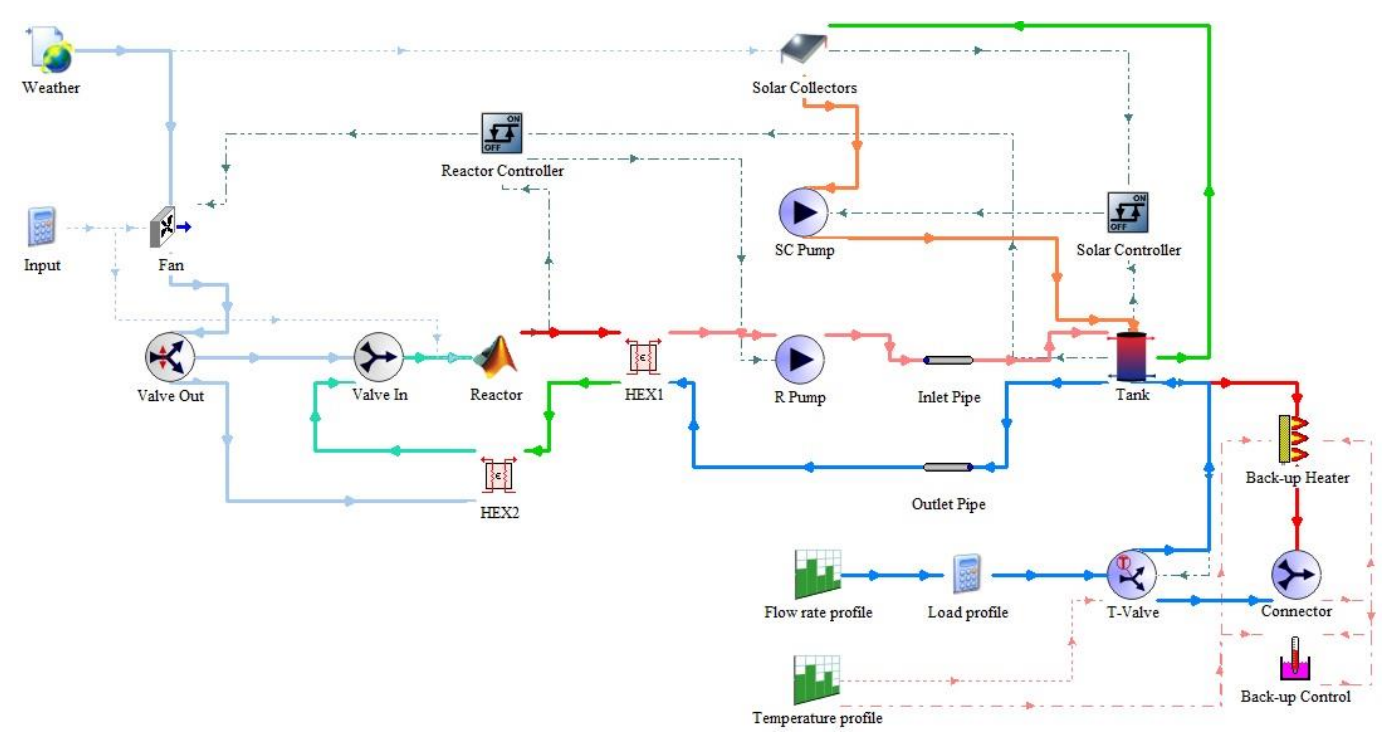

Figure 6 Principal scheme of the combined solar system for the simulation in the TRNSYS environment.

The complete control of the combined solar energy system is ensured by the elements denoted as 'Reactor Controller' and 'Solar Controller' as shown in Figure 6. The 'Reactor Controller' is used to switch on and off the 'Fan' and the 'R Pump' using the signals from the 'Reactor' and the 'Tank', while the 'Solar Controller' comprehends a typical on/off control of the 'SC Pump' in the outlet circuit of the solar collector. Additionally, the element 'Back-up Control' is used to switch on the 'Back-up Heater' in case the tank outlet temperature $T_{D H W \text {,out }}$ is below the reference temperature $T_{D H W}^{0}$. The control algorithm is described by the following logical relations. The reactor is switched on by the following condition:

$$
\gamma_{r}= \begin{cases}1, & \left(w_{v, \text { in }} \geq w_{v}^{\text {min }}\right) \wedge\left(T_{a, i n} \geq T_{a}^{\text {min }}\right) \wedge\left(\bar{T}_{D H W}<T_{D H W}^{\max }\right) \\ 0, & \left(w_{v, \text { in }}<w_{v}^{\text {min }}\right) \vee\left(T_{a, \text { in }}<T_{a}^{\text {min }}\right) \vee\left(\bar{T}_{D H W} \geq T_{D H W}^{\max }\right)\end{cases}
$$

Where $\bar{T}_{D H W}$ is the average temperature of the storage tank, $w_{v}^{\min }$ is the minimal cut-off air humidity, $T_{a}^{\min }$ is the minimal cut-off air temperature, and $T_{D H W}^{\max }$ is the maximum admissible charging temperature of the storage tank by the thermochemical modular system. The storage modules in the reactor are replaced under the following condition:

$$
\gamma_{s}= \begin{cases}1, & \left(T_{a, \text { out }}<\bar{T}_{D H W}+\Delta T_{b l}\right) \wedge\left(\bar{x}_{s}>x_{s}^{\text {min }}\right) \\ 0, & \left(T_{a, \text { out }} \geq \bar{T}_{D H W}+\Delta T_{b l}\right) \vee\left(\bar{x}_{s} \leq x_{s}^{\text {min }}\right)\end{cases}
$$

Here, $T_{a, \text { out }}$ is the air temperature at the outlet of the reactor, $\Delta T_{b l}$ is the switching hysteresis, $\bar{x}_{s}$ is the average water uptake for all storage modules in the reactor, and $x_{s}^{\min }$ is the minimal water uptake, which allows the solid to be replaced.

The heat from the solar collectors is charged to the hot water storage tank by using the typical control law of the domestic solar thermal systems, which is provided as follows:

$$
\gamma_{S C}= \begin{cases}1, & \left(T_{S C, \text { in }}<T_{S C, \text { out }}\right) \wedge\left(T_{S C, \text { in }}<T_{S C}^{\max }\right) \\ 0, & \left(T_{S C, \text { in }} \geq T_{S C, \text { out }}\right) \vee\left(T_{S C, \text { in }} \geq T_{S C}^{\max }\right)\end{cases}
$$


$T_{S C}^{\max }$ is the cut-off temperature for the solar thermal collectors. Additionally, the back-up thermal device is activated by the following control law:

$$
\gamma_{B T D}= \begin{cases}1, & T_{D H W, \text { out }}<T_{D H W}^{0} \\ 0, & T_{D H W, \text { out }} \geq T_{D H W}^{0}\end{cases}
$$

\section{Results and Discussion}

\subsection{Validation of Reactor Model}

The validation of the reactor model was completed within two stages. During the first stage, the hydration experiments were performed within the prototype installation using a single storage module (see Figure 4). The experimental data were recorded and treated by the procedure described in Section 2.3. During the second stage, the model parameters were determined. The heat transfer coefficient $h_{0}$ was calculated using the relations (11-13). Its value was identified to be invariable and equal to $524 \pm 3 \mathrm{~W} \mathrm{~K}^{-1} \mathrm{~m}^{-2}$. The kinetic coefficient $k_{0}$ was identified a posteriori from the experimental data by solving the parametric identification problem described by the relations (14-17) using Matlab ${ }^{\circledR}$. It is worth noting that the equations (14-17) represent the nonlinear least square, data-fitting problem, which was solved using the Levenberg-Marquardt algorithm. This algorithm was implemented by default in Matlab ${ }^{\circledR}$ using the LSQNONLIN solver. The experimental conditions are presented in Table 4. The parameters $b_{k}, k=0 \ldots 3$ of the kinetic model for water adsorption within the composite, which is described by equation (14), are presented in Table 5 . The comparison of the experimental kinetic coefficient $\xi_{6,1}$, calculated with equation (17) with the kinetic model $\hat{k}_{o}$ and described by equation (14), is presented in Figure 7.

Table 4 Reference conditions used in hydration experiments.

\begin{tabular}{llll}
\hline Condition & Experiment 1 & Experiment 2 & Experiment 3 \\
\hline Mass of anhydrous composite $(\mathrm{kg})$ & 2.2 & 2.1 & 2.0 \\
Initial water uptake $(\mathrm{g} / \mathrm{g})$ & $<0.01$ & 0.08 & 0.13 \\
Air volume flow rate $\left(\mathrm{m}^{3} / \mathrm{h}\right)$ & 100 & 100 & 100 \\
Air temperature at reactor inlet $\left({ }^{\circ} \mathrm{C}\right)$ & 17.1 & 10.0 & 9.5 \\
Air humidity $(\mathrm{kg} / \mathrm{kg})$ & $6.0 \times 10^{-3}$ & $5.1 \times 10^{-3}$ & $3.4 \times 10^{-3}$ \\
Water vapor pression $(\mathrm{Pa})$ & 980 & 820 & 550 \\
\hline
\end{tabular}

Table 5 Numerical values of the parameters of the kinetic model.

\begin{tabular}{cll}
\hline Parameter & Value & Units \\
\hline$b_{0}$ & $3.183 \times 10^{-4}$ & $1 / \mathrm{s}$ \\
$b_{1}$ & 0.330 & $\mathrm{~kg} / \mathrm{kg}$ \\
$b_{2}$ & 90.303 & -- \\
$b_{3}$ & 0.3253 & -- \\
\hline
\end{tabular}




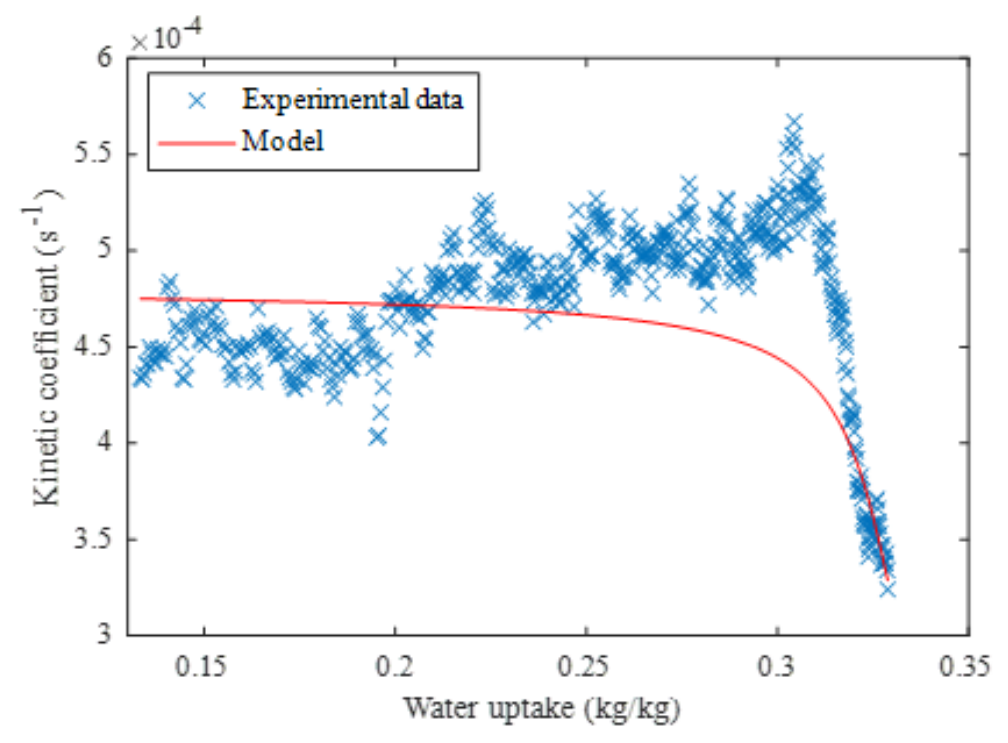

Figure 7 Validation of the kinetic model on the experimental dataset.

The analysis of the experimental data shown in Figure 7 demonstrates that the kinetic coefficient depends on the water uptake in a non-linear manner. At the beginning of the hydration process, when the water uptake is lower than $0.20 \mathrm{~kg} / \mathrm{kg}$, the kinetic coefficient remains a constant around $4.5 \times 10^{-4} 1 / \mathrm{s}$. It raises in a step-wise manner to $4.8 \times 10^{-4} 1 / \mathrm{s}$ in the range of water uptake between 0.20 and $0.25 \mathrm{~kg} / \mathrm{kg}$, and then to $5.1 \times 10^{-4} 1 / \mathrm{s}$ when the water uptake ranges from 0.25 to $0.30 \mathrm{~kg} / \mathrm{kg}$. Afterward, there is a sharp drop in the kinetic coefficient when the water uptake becomes greater than $0.30 \mathrm{~kg} / \mathrm{kg}$. Such non-linear behavior is due to the changes that occurred in the sorption mechanism. The determination of the exact cause of such a drift requires additional research on the hydro-thermal characteristics of the composite. Nevertheless, the proposed kinetic model allows the apparent kinetic coefficient to be reproduced by the sigmoid-shaped curve on account of the sharp descending front that appears at $0.30 \mathrm{~kg} / \mathrm{kg}$ of the water uptake.

With the account of identified values for both the heat transfer and kinetic coefficients, the comparison of the model with the experimental data is shown in Figure 8, Figure 9 and Figure 10. The model described in equations (5-10) was implemented and solved in Matlab ${ }^{\circledR}$ by using the ODE15i numerical algorithm to solve a set of differential equations coupled to differential-algebraic equations. The first and second derivatives over the spatial domain that are shown in Figure 5 were calculated by using three-point, second-order, finite difference approximations [22]. 


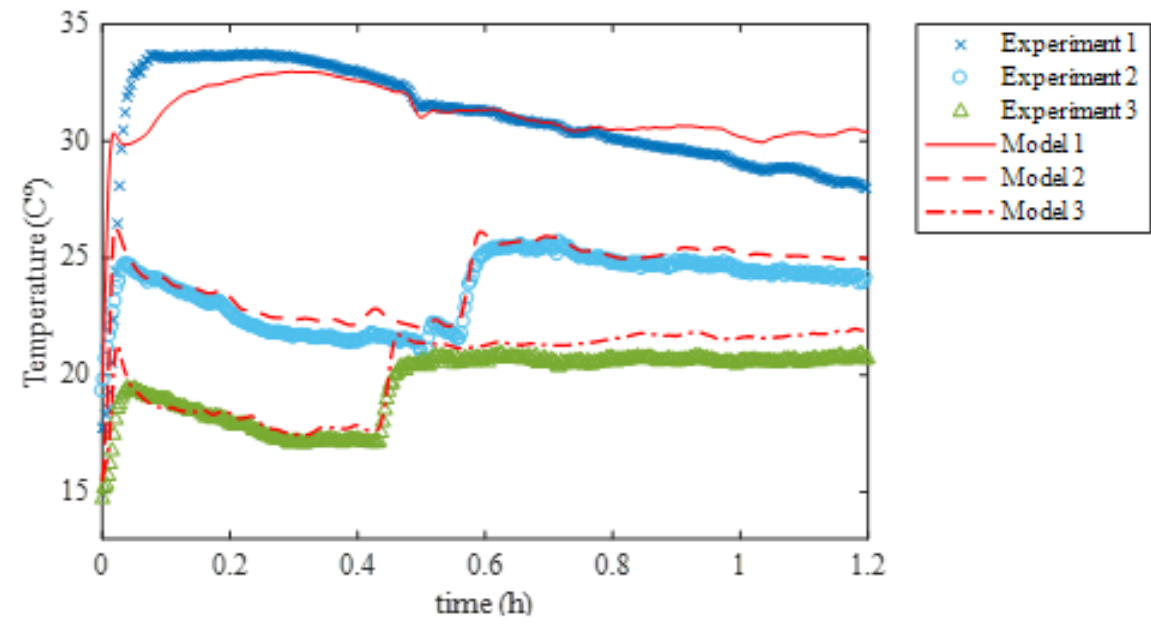

Figure 8 Air temperature at the outlet of the reactor.
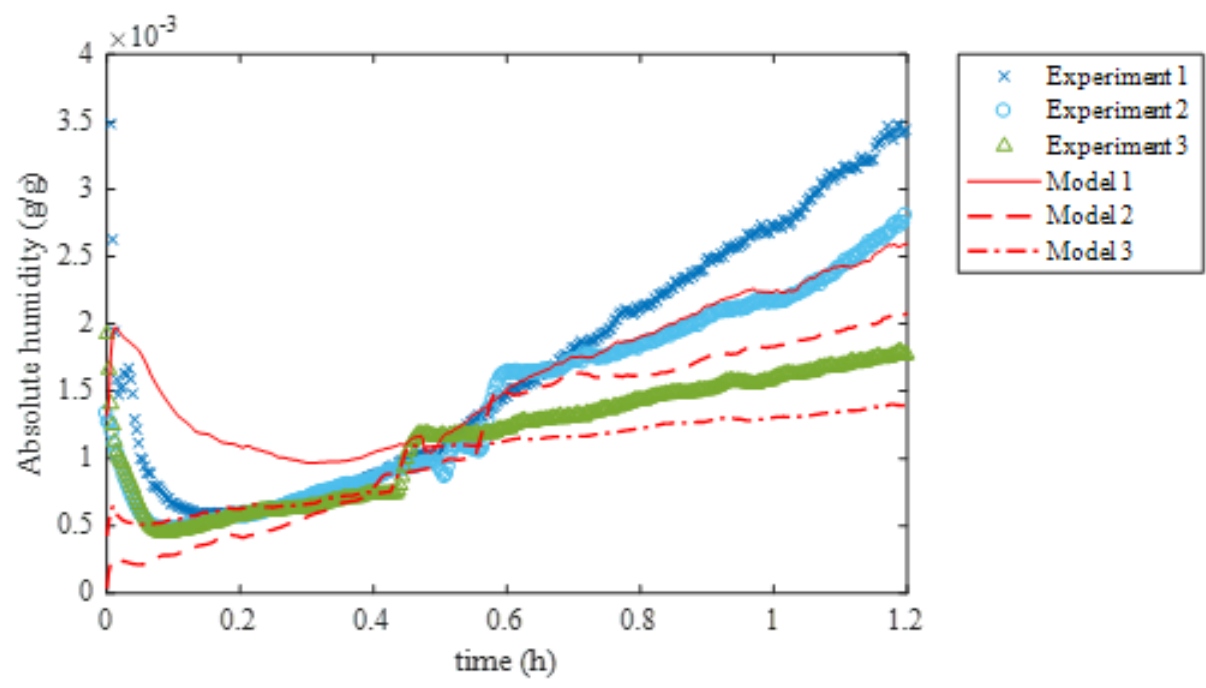

Figure 9 Absolute air humidity at the outlet of the reactor.


Figure 10 Average water uptake in the composite material. 
The validity of this model was verified by calculating the relative root-mean-squared error (RRMSE) shown as follows:

$$
R R M S E=\sqrt{\frac{\sum_{j}\left(Z_{E, j}-Z_{M, j}\right)^{2}}{\sum_{j}\left(Z_{E, j}\right)^{2}}} \times 100 \%
$$

Here, $Z_{E, j}$ is experimental data and $Z_{M, j}$ is the model output.

The curves denoted as "Model 1", "Model 2" and "Model 3" correspond to the respective number of the experiment taken from Table 4. The summary of the comparison of the model against the experimental data is presented in Table 6.

Table 6 Summary of the model validation on experimental data.

\begin{tabular}{|c|c|c|c|c|c|c|c|}
\hline \multirow[t]{2}{*}{ Result } & \multicolumn{2}{|c|}{ Experiment 1} & \multicolumn{2}{|c|}{ Experiment 2} & \multicolumn{2}{|c|}{ Experiment 3} & \multirow{2}{*}{$\begin{array}{l}\text { RRMSE } \\
(\%)\end{array}$} \\
\hline & Measured & Modelled & Measured & Modelled & Measured & Modelled & \\
\hline $\begin{array}{l}\text { Water uptake } \\
(\mathrm{kg} / \mathrm{kg})\end{array}$ & 0.29 & 0.29 & 0.34 & 0.36 & 0.33 & 0.33 & 3.6 \\
\hline $\begin{array}{l}\text { Maximal } \\
\text { thermal power } \\
\text { (W) }\end{array}$ & 550 & 499 & 471 & 476 & 307 & 305 & 6.5 \\
\hline $\begin{array}{l}\text { Average } \\
\text { thermal power } \\
\text { (W) }\end{array}$ & 384 & 401 & 309 & 350 & 173 & 208 & 10.8 \\
\hline $\begin{array}{l}\text { Thermal } \\
\text { energy } \\
\text { produced } \\
\text { (kWh) }\end{array}$ & 0.48 & 0.51 & 0.43 & 0.49 & 0.30 & 0.36 & 12.7 \\
\hline $\begin{array}{l}\text { Energy storage } \\
\text { density } \\
\left(\mathrm{kWh} / \mathrm{m}^{3}\right)\end{array}$ & 158 & 163 & 143 & 151 & 102 & 108 & 4.7 \\
\hline
\end{tabular}

As shown in Figure 8, Figure 9 and Figure 10, the model predicts the dynamics of the hydration process in the composite with high reliability. The quality of prediction for various curves and performance indicators is slightly different. Despite some differences, a high global prediction performance (see Table 6) of the model was noted since the relative root-mean-squared error (RRMSE) between the measured and modeled values was rather small and varied from $2.1 \%$ to at most $12.7 \%$. Therefore, the model is valid and can be used for dynamic simulations.

\subsection{Dynamic simulations of Typical Days}

The hydration process model in the composite, which represents one storage module in the reactor for simulation, was integrated into the TRNSYS (denoted as a "Reactor"). The entire combined solar thermal system is shown in Figure 6 . The conditions for simulation are presented in Table 7. 
Table 7 Simulation conditions used for the simulation of the combined solar system.

\begin{tabular}{ll}
\hline Condition & Value \\
\hline Geographic position & Brussels, Belgium \\
Daily hot water consumption & $217 \mathrm{~L}$ per day \\
Water temperature at the tank inlet & $10^{\circ} \mathrm{C}$ \\
Temperature range of hot water consumption & From 40 to $55^{\circ} \mathrm{C}$ \\
Position of solar thermal collectors & South, tilt about $40^{\circ}$ \\
\hline
\end{tabular}

The selection of technical parameters, as well as the sizing of components (Table 8), was carried out to achieve the fractional solar coverage for above $70 \%$. The solar collectors allow the water tank to be charged to the maximum cut-off temperature $T_{S C}^{\max }$ which is set to $95{ }^{\circ} \mathrm{C}$. The number of storage modules in the reactor is equal to 2 , which represents the compromise between the energy demand and energy production by the thermochemical system with an account of the cut-off values from the control laws present in the equations $(17,18)$. It was supposed that the minimum cut-off of the air humidity $w_{v}^{\text {min }}$ and air temperature $T_{a}^{\min }$ were $5.0 \times 10^{-3} \mathrm{~kg} / \mathrm{kg}$ and $5^{\circ} \mathrm{C}$, respectively, which meant that the reactor was switched off when one of the cut-off values was detected. At the same time, the maximum admissible charging temperature by the reactor $T_{D H W}^{\max }$ was set as $48{ }^{\circ} \mathrm{C}$, because taking into account the water uptake in non-equilibrium practical conditions, the energy storage density of the material above $40^{\circ} \mathrm{C}$ is below $100 \mathrm{kWh} / \mathrm{m}^{3}$. When the air temperature at the reactor inlet exceeds $30^{\circ} \mathrm{C}$, the storage modules must be replaced frequently to keep the water tank charged, which results in high demand for the solid. It was found that the reasonable minimum water uptake $x_{s}^{\min }$ must be not lower than $0.07 \mathrm{~kg} / \mathrm{kg}$ before the modules are replaced. To restart the reactor, the switching hysteresis $\Delta T_{b l}$ was set to $2^{\circ} \mathrm{C}$.

Table 8 Technical parameters used in the simulations.

\begin{tabular}{ll}
\hline Component & Value \\
\hline Solar thermal system & \\
Total number of solar collectors & 5 \\
Net surface area & $12.5 \mathrm{~m}^{2}$ \\
Water flow rate of the "SC Pump" & $300 \mathrm{~kg} / \mathrm{h}$ \\
Thermochemical system & \\
Number of storage modules in the reactor & 2 \\
Anhydrous solid mass per 1 module & $13 \mathrm{~kg}$ \\
Air flow rate of the fan & $968 \mathrm{~kg} / \mathrm{h}$ \\
Water flow rate of the pump "R Pump" & $235 \mathrm{~kg} / \mathrm{h}$ \\
Efficiency of the heat exchangers HX1 et HX2 & 0.9
\end{tabular}


$\underline{\text { Hot water storage tank }}$

Tank volume

3001

Back-up thermal system

Gas burner

$1000 \mathrm{~W}$

The overall control algorithm works as follows: The reactor starts to charge the cool-water storage tank during the night. As soon as the average water temperature $\bar{T}_{D H W}$ in the tank starts to reach the cut-off temperature $T_{D H W}^{\max }$ of $48{ }^{\circ} \mathrm{C}$, the daily frequency of the solid replacement $\gamma_{S}(t)$ starts to rise, and the average water uptake in all the storage modules starts to drop down to the cut-off value of $x_{s}^{\min }$ of $0.07 \mathrm{~kg} / \mathrm{kg}$. Afterward, the reactor is switched off, and the charging of the water storage tank is continued by the solar thermal collectors. It must be noted that the solar collectors allow the water storage tank to be charged independently from the thermochemical system as long as there is sufficient solar irradiance. On account of this control logic, the frequency of replacement of the storage modules can vary from 3 to 5 , which corresponds to the solid demand, which is at most $130 \mathrm{~kg}$ per day.

Given the complexity of the proposed technical system, which is composed of several adjacent sub-systems such as the solar thermal system, thermochemical system, and back-up thermal device, it is extremely difficult to analyze the simulation results every year. Because of the coupling of various components, each having its dynamic behavior, and control laws, it is necessary to simplify the analysis of system dynamics for the sake of determining the most significant factors. Such a simplification is possible during the days that have a typical climate. Moreover, the dynamic behavior of the thermochemical energy storage is made the focus of the present study. The climate data includes many variables. The selection of the climatic conditions is not a trivial task, given that there exists a huge number of possible combinations between these variables. In the context of the study of the dynamic behavior of thermochemical energy storage, the most important climate variables are air temperature and air humidity. The days having a typical climate have climatic conditions that are defined as having a high probability of occurrence for the thermochemical energy storage system to be active during the year. For demonstration, three typical days denoted as 'cold day', 'mild day', and 'warm day' are selected, for which the dynamic behavior of the combined solar system was simulated. The selection of the typical days was performed when the values of both the air temperature and air humidity occurred not less than $16 \mathrm{~h}$ during each calendar day. The $16 \mathrm{~h}$ duration corresponds to the probability of occurrence of not less than $67 \%$ of the air temperature and air humidity, which also ensures a $100 \%$ probability for the thermochemical system to be activated. The typical days along with the temperature and air humidity range that are chosen for the simulations, are presented in Table 9.

Table 9 Typical climate days used in dynamic simulations of the combined solar system.

\begin{tabular}{|c|c|c|c|c|c|}
\hline Notation & $\begin{array}{l}\text { Representative } \\
\text { Date }\end{array}$ & $\begin{array}{l}\text { Temperature } \\
\text { range }\left({ }^{\circ} \mathrm{C}\right)\end{array}$ & $\begin{array}{l}\text { Air } \\
\text { range } \\
\text { (kg/kg) }\end{array}$ & $\begin{array}{r}\text { humidity } \\
\times 10^{-3}\end{array}$ & Probability \\
\hline
\end{tabular}




\begin{tabular}{lllll}
\hline "Cold day" & 31 October & $2.71 \ldots 8.27$ & $4.57 \ldots 7.8$ & $70 \%$ \\
"Mild day" & 14 April & $8.27 \ldots 13.8$ & $4.57 \ldots 7.8$ & $82 \%$ \\
"Warm day" & 29 May & $13.8 \ldots 19.4$ & $4.57 \ldots 7.8$ & $22 \%$ \\
\hline
\end{tabular}

It must be noted that the probability of occurrence of a so-called "warm day" is only $22 \%$, despite wide ranges of air temperature and air humidity. However, in the mild climate of Brussels location (Belgium), this condition usually coincides with rainy and cloudy days, which almost excludes the participation of the solar collectors from the tank charging process. It is clear that with the limitations imposed by the control laws, the thermochemical energy storage system would not be able to charge the water storage tank beyond $48{ }^{\circ} \mathrm{C}$, and the back-up thermal device will automatically be activated in place of the solar thermal collectors. The simulation results are discussed here below and are shown in Figure 11, 12, .., 19. The curves denoted as "Tank Node 15 " represent the temperature of water at specific points within the water storage tank along the vertical axis, which were modeled using the TRNSYS software. The curve "Hot Water Temperature" represents the domestic hot water consumption profile. The curve "Reactor Temperature" is regarding the air temperature at the reactor outlet. The curve "Solar Collectors Temperature" represents the temperature of the fluid at the outlet of the solar thermal collectors.

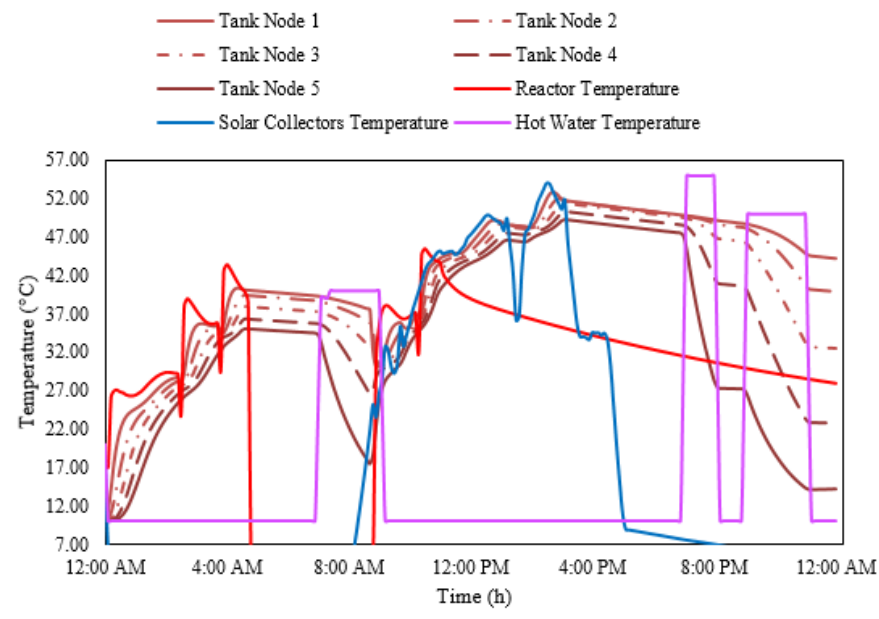

Figure 11 Temperature profiles in the combined solar system during a "cold day".

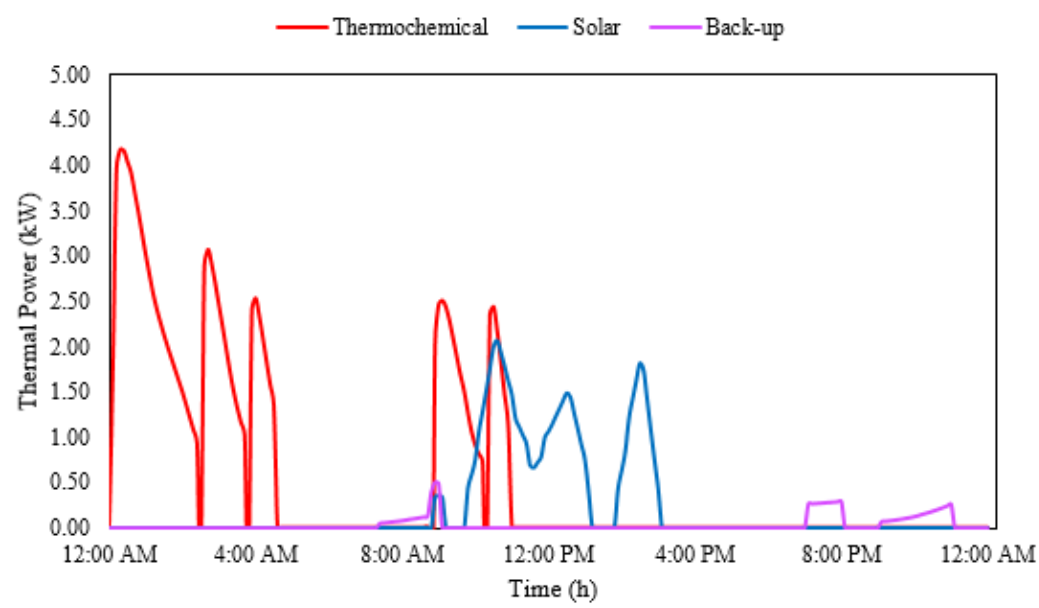


Figure 12 Thermal power profiles in the combined solar system during a "cold day".

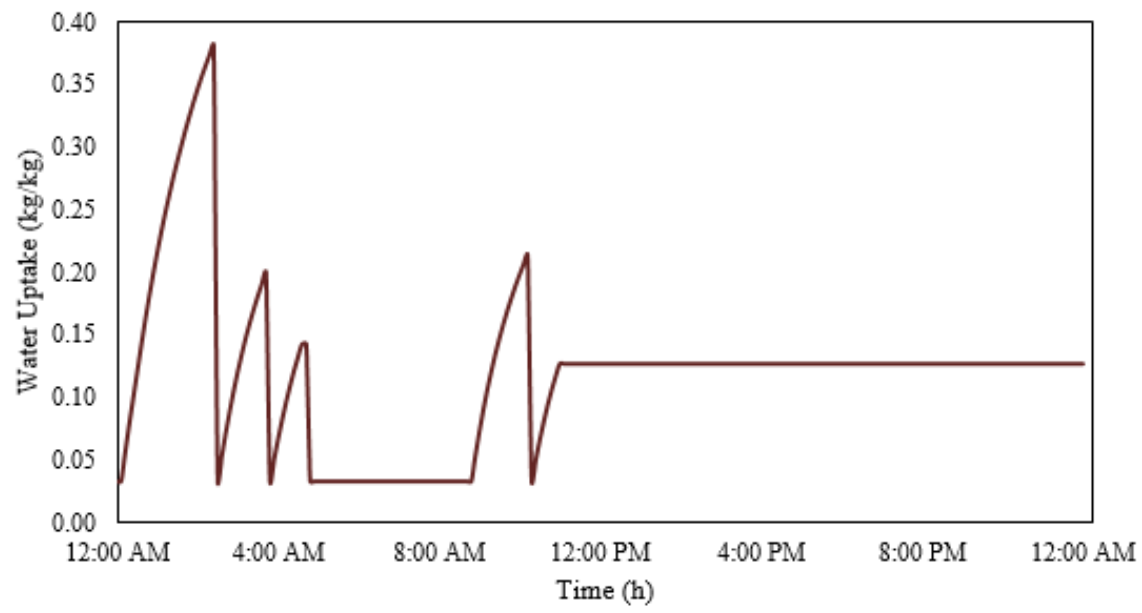

Figure 13 Water uptake in the solid during a "cold day".

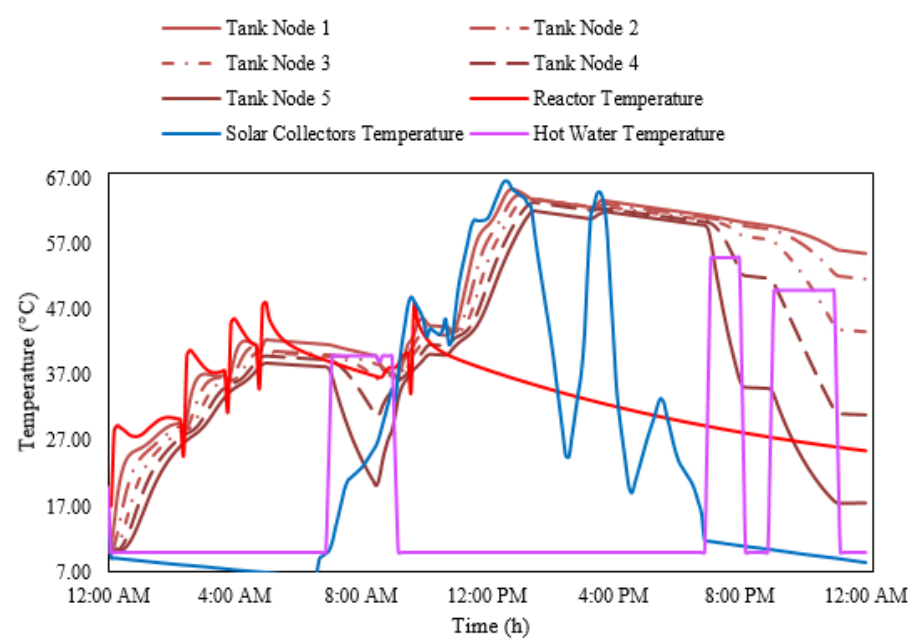

Figure 14 Temperature profiles in the combined solar system during a "mild day".

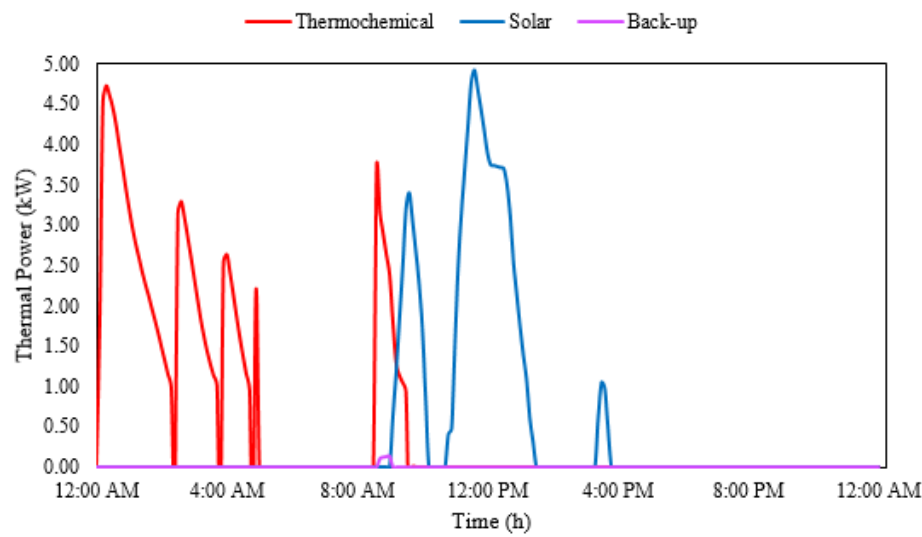

Figure 15 Thermal power profiles in the combined solar system during a "mild day". 


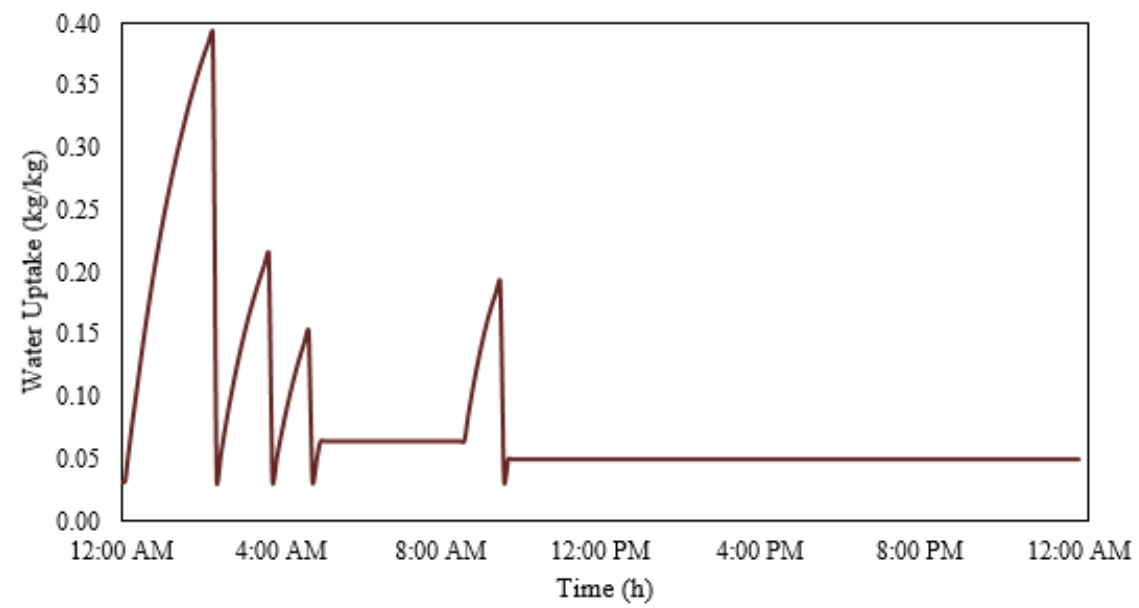

Figure 16 Water uptake in the solid during a "mild day".

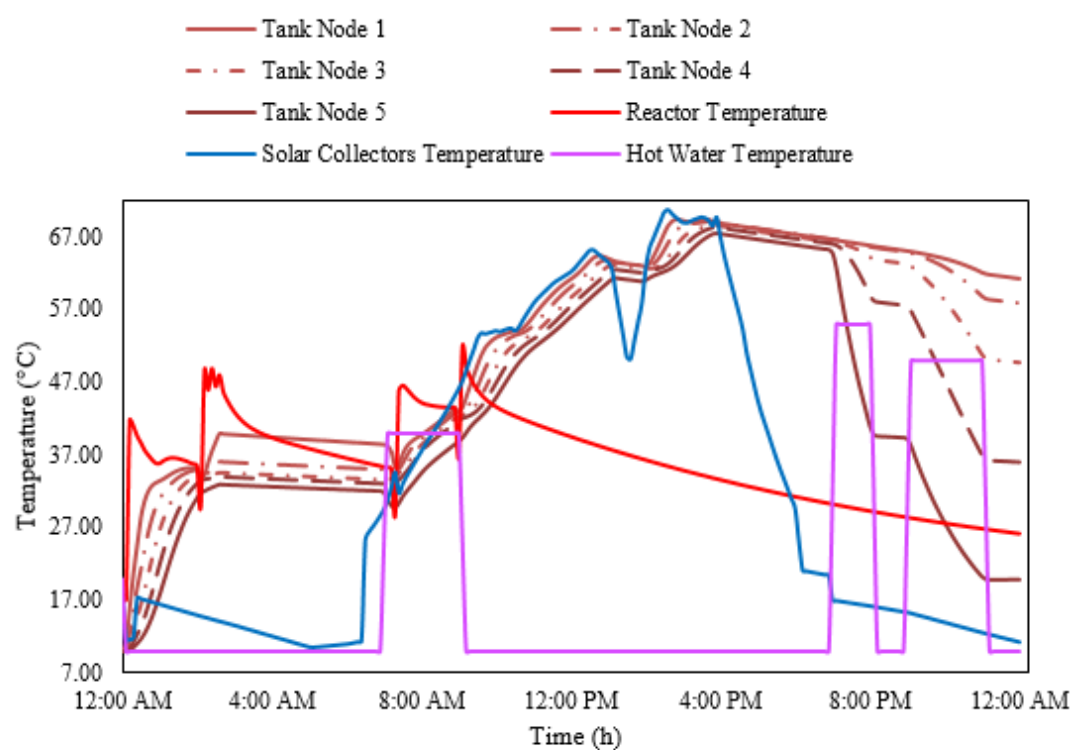

Figure 17 Temperature profiles in the combined solar system during a "warm day".

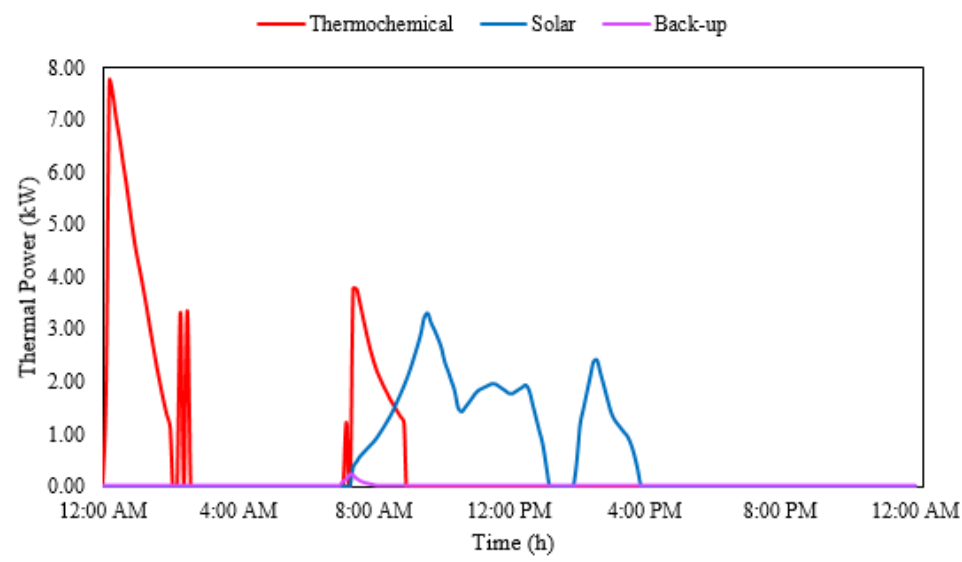


Figure 18 Thermal power profiles in the combined solar system during a "warm day".

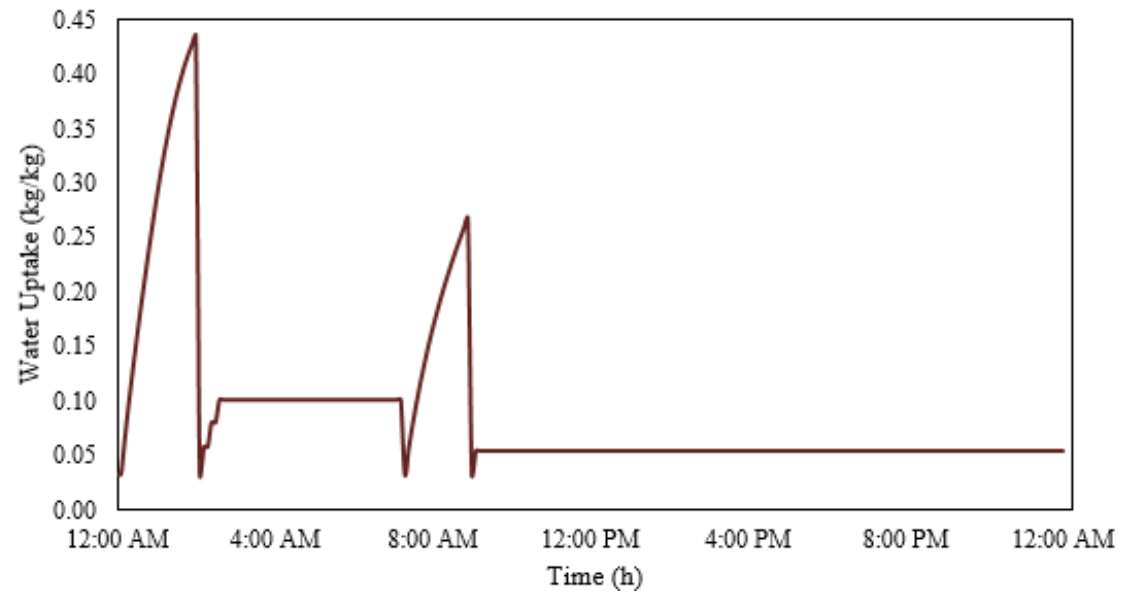

Figure 19 Water uptake in the solid during a "warm day".

\subsubsection{Simulation of a "Cold Day"}

This typical day is characterized by the air temperature fluctuating between $3{ }^{\circ} \mathrm{C}$ and $10{ }^{\circ} \mathrm{C}$, whereas the air humidity remains at about $5.2 \times 10^{-3} \mathrm{~kg} / \mathrm{kg}$. The water storage tank starts charging from $10{ }^{\circ} \mathrm{C}$ by the thermochemical reactor. The temperature in the tank rises to $40{ }^{\circ} \mathrm{C}$ during $4 \mathrm{~h}$ before the early consumption of hot water, which starts at 6:00 am (see Figure 11). Between 4:00 and 6:00 am, the combined system is halted because the maximum achievable temperature is limited to $48^{\circ} \mathrm{C}$. The temperature in the water storage tank is maintained at $40^{\circ} \mathrm{C}$ at the top layer (see Figure 11). The maximal thermal power injected by the thermochemical system in the water tank reduces from $4.15 \mathrm{~kW}$ to $2.5 \mathrm{~kW}$ along with the thermal charge of the tank due to the natural decrease of the adsorption capacity related to the water sorption equilibrium (see Figure 12). The working cycle of the reactor becomes shorter after every solid replacement. The average water uptake in the solid also reduces from $0.38 \mathrm{~kg} / \mathrm{kg}$ to $0.14 \mathrm{~kg} / \mathrm{kg}$ (see Figure 13). As a result, the energy storage density in the solid already drops down from $214 \mathrm{kWh} / \mathrm{m}^{3}$ to $79 \mathrm{kWh} / \mathrm{m}^{3}$ during the first 4 $\mathrm{h}$ of charging of the tank. Some amount of heat lesser than $500 \mathrm{~W}$ is supplied by the back-up thermal device at 6:00 am to compensate for a small amount of thermal loss in the water tank (see Figure 12). At 8:00 am, all adjacent systems work simultaneously. Technically, this is not a conflictual situation; however, the control algorithm must be improved to avoid this type of situation. The thermal charging of the water storage tank is prioritized by the solar collectors from 9:00 am to 3:00 $\mathrm{pm}$ so that the temperature in the tank increases up to $50{ }^{\circ} \mathrm{C}$ (see Figure 11). The thermochemical reactor is deactivated from 5:00 pm because the air humidity drops below the cut-off limit of $5.0 \times 10^{-3} \mathrm{~kg} / \mathrm{kg}$. The back-up thermal device is activated from 7:00 pm to 9:00 pm (see Figure 12), supplying at most $380 \mathrm{~W}$ of the thermal power.

\subsubsection{Simulation of a "Mild Day"}

This typical climate day is characterized by the variation in the air temperature ranging from $6.4{ }^{\circ} \mathrm{C}$ to $14.3^{\circ} \mathrm{C}$. The air humidity fluctuates within the range of $5.6 \times 10^{-3} \mathrm{~kg} / \mathrm{kg}$ to $6.4 \times 10^{-3}$ $\mathrm{kg} / \mathrm{kg}$. Similarly, the charging of the water tank is ensured by the thermochemical reactor from 0:00 
am to 5:00 am until the temperature in the top layer of the tank reaches $42.3{ }^{\circ} \mathrm{C}$ and the temperature at the reactor outlet crosses the cut-off limit (see Figure 14). During this period, the thermal power at the outlet of the thermochemical system reduces from 4.5 to $2.2 \mathrm{~kW}$ (see Figure 15), and the solid in the reactor is replaced four times before using the hot water (see Figure 16). The energy storage density of the material reduces from $221.5 \mathrm{kWh} / \mathrm{m}^{3}$ after the first replacement to $86.5 \mathrm{kWh} / \mathrm{m}^{3}$ after the third replacement. The fourth reactor switching cycle occurs at about 4:45 am. However, the reactor works only for $12 \mathrm{~min}$ before the temperature at the outlet of the reactor reaches the cut-off limit. In such conditions, the water uptake is as high as $0.064 \mathrm{~kg} / \mathrm{kg}$. The reactor is temporarily stopped, and then it restarts later at 8:35 am. The final water uptake is about 0.19 $\mathrm{kg} / \mathrm{kg}$, while the energy storage density in the solid is $108.8 \mathrm{kWh} / \mathrm{m}^{3}$. It must be noted that the reactor is switched on for the fifth time at 9:00 am (see Figure 15 and Figure 16), but the control algorithm does not allow the reactor to run in the present conditions. The next working cycle is postponed to the next day. The solar collectors continue the thermal charge of the water storage tank from 9:00 am to 3:00 pm. The peak thermal power attains $4.92 \mathrm{~kW}$ at 11:00 am (see Figure 15). The amount of thermal energy produced by the solar collectors is high enough to charge the water tank up to $63{ }^{\circ} \mathrm{C}$. The back-up heater is only used for $25 \mathrm{~min}$ to compensate for the difference of about $130 \mathrm{~W}$ (see Figure 15).

\subsubsection{Simulation of a "Warm Day"}

In this case of simulation, the air temperature varies within the range of $10.2^{\circ} \mathrm{C}$ to $19.1{ }^{\circ} \mathrm{C}$, while the air humidity ranges from $6.6 \times 10^{-3} \mathrm{~kg} / \mathrm{kg}$ to $9.8 \times 10^{-3} \mathrm{~kg} / \mathrm{kg}$. First, the control algorithm activates the thermochemical system that works till 2:30 am. By this time, the temperature of water at the top layer of the tank reaches $40^{\circ} \mathrm{C}$ (see Figure 17). Such a prompt rise in temperature is due to the high humidity content, which is $9.0 \times 10^{-3} \mathrm{~kg} / \mathrm{kg}$, which leads to the high equilibrium uptake (see adsorption isotherm curves in Figure 3 ) and to a high thermal power output by the reactor. Indeed, the thermal power reaches $7.7 \mathrm{~kW}$ (see Figure 18). Under such a condition, the water uptake in the solid is as high as $0.44 \mathrm{~kg} / \mathrm{kg}$, while the energy storage density in the solid is $247.3 \mathrm{kWh} / \mathrm{m}^{3}$. It is worth noting that the high humidity content results in the frequent on/off switching of the reactor (see Figure 17, Figure 18 and Figure 19). The reactor works under unfavorable conditions because the water uptake in the solid reaches only $0.1 \mathrm{~kg} / \mathrm{kg}$ and because the energy storage density of the material is only $56.2 \mathrm{kWh} / \mathrm{m}^{3}$. The reactor continues to work around 7:20 am for $1.7 \mathrm{~h}$ (see Figures 17, Figure 18 and Figure 19). All three adjacent systems are activated simultaneously for 1.2 $\mathrm{h}$ (see Figure 18). The thermal power produced by the back-up heating device is limited by $214 \mathrm{~W}$ at most. Afterward, the solar collectors constitute a major part of the daily energy demand. The water temperature in the storage tank reaches $68^{\circ} \mathrm{C}$ around $2: 00 \mathrm{pm}$. Finally, the solar collectors are deactivated after $4: 00 \mathrm{pm}$, leaving the water tank to be fully charged till the end of the day (see Figure 17).

\subsection{Summary of Energy Performance}

The overview of the simulation results is presented in Table 10 in the form of performance indicators. The performance indicators for the thermochemical system were calculated using equations (1-4). The amount of energy produced by the solar collectors and back-up heater was 
determined with the help of TRNSYS by using the built-in integrator function plugged into the concerned component, as shown in Figure 6.

Table 10 Summary of the simulation results for the combined solar system under days of typical climate.

\begin{tabular}{|c|c|c|c|}
\hline \multirow[t]{2}{*}{ Performance indicator } & \multicolumn{3}{|l|}{ Value } \\
\hline & "Cold day" & "Mild day" & "Warm day" \\
\hline \multicolumn{4}{|l|}{ Thermochemical system } \\
\hline Thermal energy produced by the system (kWh) & 12.95 & 12.94 & 12.66 \\
\hline Total solid mass (kg) & 130 & 104 & 78 \\
\hline \multicolumn{4}{|l|}{$\begin{array}{l}\text { Energy storage density in the solid per lot } \\
\left(\mathrm{kWh} / \mathrm{m}^{3}\right) \text { : }\end{array}$} \\
\hline$-\operatorname{lot} 1$ & 214.7 & 221.5 & 247.3 \\
\hline$-\operatorname{lot} 2$ & 112.1 & 121.1 & 56.2 \\
\hline$-\operatorname{lot} 3$ & 79.4 & 86.5 & 150 \\
\hline$-\operatorname{lot} 4$ & 119.4 & 108.8 & -- \\
\hline$-\operatorname{lot} 5$ & 71 & -- & -- \\
\hline \multicolumn{4}{|l|}{$\underline{\text { Solar thermal system }}$} \\
\hline Thermal energy produced by the system (kWh) & 5.4 & 10.4 & 12.8 \\
\hline \multicolumn{4}{|l|}{ Back-up thermal system } \\
\hline $\begin{array}{l}\text { Energy supplement produced by the system } \\
\text { (kWh) }\end{array}$ & 0.87 & 0.05 & 0.11 \\
\hline
\end{tabular}

It is worth noting that a "lot" comprises the solid mass contained in each storage module in the reactor. The actual model accounts for the homogeneous water sorption in the solid material, and therefore the average water uptake remains equal in each of the storage modules. The amount of thermal energy produced by the thermochemical system is almost in the same order for each typical day and varies from 12.66 to $12.95 \mathrm{kWh}$. Such an insignificant difference can be related to the cutoff temperature limit of the reactor, which was set as $48{ }^{\circ} \mathrm{C}$. Despite this fact, the replacement frequency of the lot is not the same, and it depends on the air temperature and air humidity at the inlet of the reactor. During the "cold day", the air humidity used during the simulation was about $5.2 \times 10^{-3} \mathrm{~kg} / \mathrm{kg}$, and the air temperature was below $10{ }^{\circ} \mathrm{C}$. Under such a circumstance, the temperature at the reactor outlet cannot reach the cut-off temperature, which results in a high frequency of solid replacement. On the contrary, during a "warm day", the reactor works under conditions with relatively high humidity content and air temperature, which results in the high output of thermal power and high switching frequency of the reactor. For this kind of condition, the parameters in the control law in equation (17) must be respectively adjusted in such a manner to avoid frequent on/off running cycles in the reactor. This means that the cut-off temperature of the reactor must be placed higher than $48{ }^{\circ} \mathrm{C}$. At the same time, the cut-off temperature must be 
lowered during conditions of little humidity content in the air to avoid too many replacements of lots.

It is important to address the disinfection problem of the water storage tank. The growth of pathogens in the water storage tank and water distribution system requires special studies, including the collection of experimental data and validation of the thermal management algorithm. This topic was not included in the present study because the primary focus was on the determination of the energy performance characteristics of the thermochemical reactor. Nevertheless, basic conditions and measures were taken for the thermal disinfection of the water storage tank, because the water temperature in the tank was periodically heated above $60{ }^{\circ} \mathrm{C}$ (see Figure 14 and Figure 17).

\section{Conclusions}

In this paper, the prototype of the combined solar thermochemical system was fully built and instrumented. The single storage module filled with $2.2 \mathrm{~kg}$ of composite thermochemical material was experimentally tested. The energy storage density in the material under experimental nonequilibrium conditions varied between 102 and $158 \mathrm{kWh} / \mathrm{m}^{3}$. The average thermal power was measured as high as $384 \mathrm{~W}$ for the range having a higher air humidity, and it was about $173 \mathrm{~W}$ for the range having a lower air humidity. These numbers showed great applied interest for the validation of the theoretical model of the adsorption process. The validation of the mathematical model for the adsorption of water vapor in a composite was carried out. It was concluded that the proposed kinetic model was valid and allowed the dynamics of the adsorption process to be predicted with high reliability. Finally, the simulator of the combined system was built using the TRNSYS software. The study of the thermal charge of the water storage tank for domestic hot water production was performed under conditions represented during typical climatic days. It was found that the performance indicators highly depended on the control algorithm, especially for thermochemical energy storage. Additional research about the improvement of the control algorithm is required.

\section{Nomenclature}

\begin{tabular}{|c|c|c|c|c|}
\hline \multicolumn{5}{|c|}{ Abbreviations } \\
\hline BTD & Back-up thermal device & & $P$ & Hydraulic pump \\
\hline DHW & Domestic hot water & & SC & Solar thermal collectors \\
\hline $\mathrm{F}$ & Fan & & SM & Storage module \\
\hline$H X$ & Heat exchanger & & RRMSE & Relative root-mean squared error \\
\hline \multicolumn{5}{|c|}{ Symbols } \\
\hline$a, b$ & Constants & & $\mu$ & Dynamic viscosity $(\mathrm{Pa} / \mathrm{s})$ \\
\hline$C_{\mathrm{P}}$ & Heat capacity $(\mathrm{W} / \mathrm{kg} / \mathrm{K})$ & & $N u$ & Nusselt number \\
\hline$D_{L}$ & Diffusivity $\left(\mathrm{m}^{2} / \mathrm{s}\right)$ & & $\operatorname{Pr}$ & Prandtl number \\
\hline$\Delta$ & Difference operator & & $p$ & Partial gas pressure $(\mathrm{Pa})$ \\
\hline$\Delta E_{r}$ & $\begin{array}{ll}\text { Energy } & \text { storage } \\
\left(\mathrm{kWh} / \mathrm{m}^{3}\right) & \end{array}$ & density & $\dot{Q}$ & Thermal power (W) \\
\hline$\Delta H_{s}$ & Reaction heat $(\mathrm{J} / \mathrm{kg})$ & & Re & Reynolds number \\
\hline$E$ & Energy (kWh) & & $\rho$ & Specific mass $\left(\mathrm{kg} / \mathrm{m}^{3}\right)$ \\
\hline
\end{tabular}




\begin{tabular}{|c|c|c|c|}
\hline$\varepsilon$ & Porosity & $S$ & Sutherland constant $(\mathrm{K})$ \\
\hline$\gamma$ & Logical variable & $T$ & Temperature $\left({ }^{\circ} \mathrm{C}\right)$ \\
\hline$h_{0}$ & Heat transfer coefficient (W/K) & $t$ & Time (s) \\
\hline$k_{o}$ & Kinetic coefficient $(1 / \mathrm{s})$ & $u$ & Linear velocity $(\mathrm{m} / \mathrm{s})$ \\
\hline$\lambda_{L}$ & Thermal diffusivity $\left(\mathrm{m}^{2} / \mathrm{s}\right)$ & $w$ & Air humidity $(\mathrm{kg} / \mathrm{kg})$ \\
\hline$M$ & Molar mass $(\mathrm{kg} / \mathrm{mol})$ & $X_{m}$ & Molar fraction $(\mathrm{mol} / \mathrm{mol})$ \\
\hline$m$ & Mass (kg) & $x$ & Water uptake $(\mathrm{kg} / \mathrm{kg})$ \\
\hline$\dot{m}$ & Mass flow rate $(\mathrm{kg} / \mathrm{s})$ & $x_{s}^{0}$ & Adsorption equilibrium $(\mathrm{kg} / \mathrm{kg})$ \\
\hline$Z$ & Denotes data in a data vector & & \\
\hline \multicolumn{4}{|c|}{ Subscripts } \\
\hline a & Refers to air & M & Refers to modeled data \\
\hline bed & Indicates storage module (bed) & out & Indicates output \\
\hline BTD & $\begin{array}{l}\text { Indicates back-up thermal } \\
\text { device }\end{array}$ & $\mathrm{p}$ & $\begin{array}{l}\text { Refers to the particle } \\
\text { characteristics }\end{array}$ \\
\hline DHW & Refers to domestic hot water & r & Refers to thermochemical reactor \\
\hline $\mathrm{E}$ & Refers to experimental data & s & Refers to solid material \\
\hline g & Refers to gas mixture & SC & Refers to solar thermal collectors \\
\hline in & Indicates input & $v$ & Refers to water vapor \\
\hline \multicolumn{4}{|c|}{ Superscripts } \\
\hline \multirow[t]{2}{*}{0} & reference & $\min$ & Minimum threshold \\
\hline & equilibrium state & & \\
\hline $\max$ & Maximum threshold & & \\
\hline
\end{tabular}

\section{Acknowledgments}

Authors thank the BESOL (Rochefort, Belgium) team for the partnership in manufacturing and mounting of the prototype. Authors acknowledge Solvay for the provision of Caso ${ }^{\circledR}$ granules.

\section{Author Contributions}

Conceptualization, methodology, writing original draft, O.S.; Composite material curation, E.C.; Visualization, validation, writing review and editing, E.C., N.H., M.F.; Conceptualization, supervision, project administration, funding acquisition, M.F.

\section{Funding}

This research was funded by European Regional Development Fund and Wallonia Region, project reference FEDER C3E2D-STOCC.

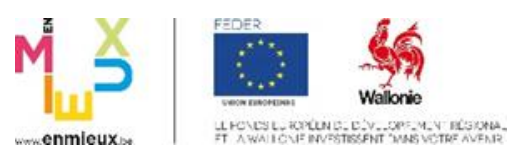

\section{Competing Interests}

The authors have declared that no competing interests exist. 


\section{References}

1. Rockenfeller V, Kirol LD, Ryan WA. Solid-gas chemisorption; efficient HVAC and R without CFCs. ASHRAE J. 1992; 34: 54-58.

2. Srivastava NC, Eames IW. A review of adsorbents and adsorbates in solid-vapour adsorption heat pump systems. Appl Therm Eng. 1998; 18: 707-714.

3. Clark RJ, Mehrabadi A, Farid M. State of the art on salt hydrate thermochemical energy storage systems for use in building applications. J Energy Storage. 2020; 27: 101145.

4. Scapino L, Zondag HA, Van Bael J, Diriken J, Rindt CC. Energy density and storage capacity cost comparison of conceptual solid and liquid sorption seasonal heat storage systems for lowtemperature space heating. Renew Sust Energ Rev. 2017; 76: 1314-1331.

5. Pinheiro JM, Salústio $S$, Rocha J, Valente $A A$, Silva $C M$. Adsorption heat pumps for heating applications. Renew Sust Energ Rev. 2020; 119: 109528.

6. Roumpedakis TC, Kallis G, Magiri-Skouloudi D, Grimekis D, Karellas S. Life cycle analysis of ZEOSOL solar cooling and heating system. Renew Energ. 2020; 154: 82-98.

7. Wang RZ, Li M, Xu YX, Wu JY. An energy efficient hybrid system of solar powered water heater and adsorption ice maker. Sol Energy. 2000; 68: 189-195.

8. Ji X, Song X, Li M, Liu J, Wang Y. Performance investigation of a solar hot water driven adsorption ice-making system. Energy Convers Manag. 2015; 106: 759-765.

9. Zhao YJ, Wang RZ, Li TX, Nomura Y. Investigation of a $10 \mathrm{kWh}$ sorption heat storage device for effective utilization of low-grade thermal energy. Energy. 2016; 113: 739-747.

10. Zhang $\mathrm{Y}$, Wang R. Sorption thermal energy storage: Concept, process, applications and perspectives. Energy Stor Mater. 2020; 27: 352-369.

11. Gaeini M, van Alebeek R, Scapino L, Zondag HA, Rindt CC. Hot tap water production by a $4 \mathrm{~kW}$ sorption segmented reactor in household scale for seasonal heat storage. J Energy Storage. 2018; 17: 118-128.

12. Michel B, Mazet N, Neveu P. Experimental investigation of an open thermochemical process operating with a hydrate salt for thermal storage of solar energy: Local reactive bed evolution. Appl Energy. 2016; 180: 234-244.

13. Aydin D, Casey SP, Chen X, Riffat S. Novel "open-sorption pipe" reactor for solar thermal energy storage. Energy Convers Manag. 2016; 121: 321-334.

14. Bertsch F, Jaehnig D, Asenbeck S, Kerskes H, Drueck H, Wagner W, et al. Comparison of the thermal performance of a solar heating system with open and closed solid sorption storage. Energy Procedia. 2014; 48: 280-289.

15. Palomba V, Frazzica A. Comparative analysis of thermal energy storage technologies through the definition of suitable key performance indicators. Energy Build. 2019; 185: 88-102.

16. Skrylnyk O, Courbon E, Heymans N, Frere M, Bougard J, Descy G. Performance characterization of salt-in-silica composite materials for seasonal energy storage design. J Energy Storage. 2018; 19: 320-336.

17. Wyttenbach J, Bougard J, Descy G, Skrylnyk O, Courbon E, Frère M, et al. Performances and modelling of a circular moving bed thermochemical reactor for seasonal storage. Appl Energy. 2018; 230: 803-815.

18. Courbon E, D'Ans P, Permyakova A, Skrylnyk O, Steunou N, Degrez M, et al. Further improvement of the synthesis of silica gel and $\mathrm{CaCl}_{2}$ composites: Enhancement of energy storage density and 
stability over cycles for solar heat storage coupled with space heating applications. Sol Energy. 2017; 157: 532-541.

19. Pearson JR. A note on the "Danckwerts" boundary conditions for continuous flow reactors. Chem Eng Sci. 1959; 10: 281-284.

20. Wakao N, Funazkri T. Effect of fluid dispersion coefficients on particle-to-fluid mass transfer coefficients in packed beds: Correlation of Sherwood numbers. Chem Eng Sci. 1978; 33: 13751384.

21. Buddenberg JW, Wilke CR. Calculation of gas mixture viscosities. Ind Eng Chem Res. 1949; 41: 1345-1347.

22. Bickley WG. Formulae for numerical differentiation. Math Gazette. 1941; 25: 19-27.

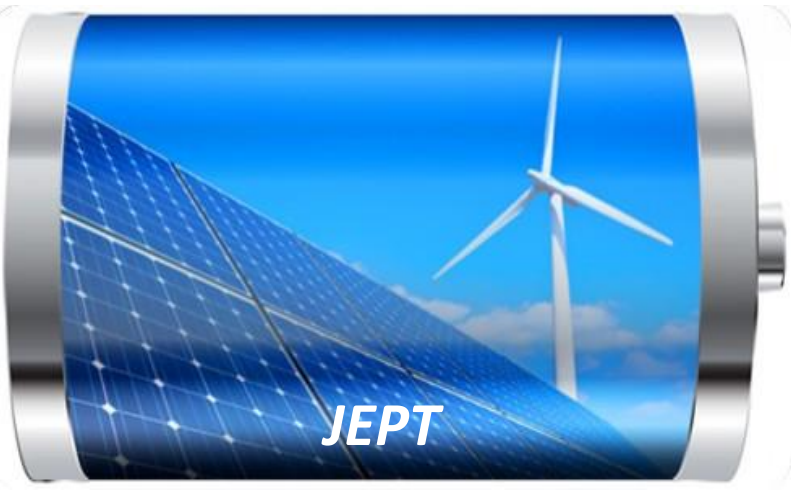

Enjoy JEPT by:

1. Submitting a manuscript

2. Joining in volunteer reviewer bank

3. Joining Editorial Board

4. Guest editing a special issue

For more details, please visit: http://www.lidsen.com/journal/jept 